Review article

\title{
Establishing moderators and biosignatures of antidepressant response in clinical care (EMBARC): Rationale and design
}

\author{
Madhukar H. Trivedi a, *, Patrick J. McGrath ${ }^{\text {b }}$, Maurizio Fava ${ }^{c}$, Ramin V. Parsey ${ }^{\text {d, }}$ \\ Benji T. Kurian a ${ }^{a}$, Mary L. Phillips ${ }^{\mathrm{e}}$, Maria A. Oquendo ${ }^{\mathrm{b}}$, Gerard Bruder ${ }^{\mathrm{b}}$, Diego Pizzagalli ${ }^{\mathrm{f}}$, \\ Marisa Toups ${ }^{a}$, Crystal Cooper ${ }^{a}$, Phil Adams ${ }^{b}$, Sarah Weyandt ${ }^{a}$, David W. Morris ${ }^{a}$, \\ Bruce D. Grannemann ${ }^{\mathrm{a}}$, R. Todd Ogden ${ }^{\mathrm{g}}$, Randy Buckner ${ }^{\mathrm{h}}$, Melvin McInnis ${ }^{\mathrm{i}}$, \\ Helena C. Kraemer ${ }^{\mathrm{j}}$, Eva Petkova ${ }^{\mathrm{k}}$, Thomas J. Carmody ${ }^{\mathrm{a}}$, Myrna M. Weissman ${ }^{\mathrm{b}}$ \\ ${ }^{a}$ University of Texas, Southwestern Medical Center, Dallas, TX, USA \\ ${ }^{\mathrm{b}}$ New York State Psychiatric Institute \& Department of Psychiatry, College of Physicians and Surgeons of Columbia University, New York, NY, USA \\ ${ }^{c}$ Massachusetts General Hospital, Boston, MA, USA \\ d Stony Brook University, Stony Brook, NY, USA \\ e University of Pittsburgh, Pittsburgh, PA, USA \\ ${ }^{\mathrm{f}}$ Harvard Medical School - McLean Hospital, Boston, MA, USA \\ g Columbia University, New York, NY, USA \\ ${ }^{\mathrm{h}}$ Harvard University, Cambridge, MA, USA \\ ${ }^{\mathrm{i}}$ University of Michigan, Ann Arbor, MI, USA \\ jStanford University, Stanford, CA, USA \\ ${ }^{\mathrm{k}}$ New York University, New York, NY, USA
}

\section{A R T I C L E I N F O}

\section{Article history:}

Received 3 February 2014

Received in revised form

2 March 2016

Accepted 3 March 2016

\section{Keywords:}

Biosignatures

Antidepressant response

Moderators

Mediators

EMBARC

Sertraline

\begin{abstract}
A B S T R A C T
Remission rates for Major Depressive Disorder (MDD) are low and unpredictable for any given antidepressant. No biological or clinical marker has demonstrated sufficient ability to match individuals to efficacious treatment. Biosignatures developed from the systematic exploration of multiple biological markers, which optimize treatment selection for individuals (moderators) and provide early indication of ultimate treatment response (mediators) are needed. The rationale and design of a multi-site, placebocontrolled randomized clinical trial of sertraline examining moderators and mediators of treatment response is described. The target sample is 300 participants with early onset ( $\leq 30$ years) recurrent MDD. Non-responders to an 8-week trial are switched double blind to either bupropion (for sertraline nonresponders) or sertraline (for placebo non-responders) for an additional 8 weeks. Clinical moderators include anxious depression, early trauma, gender, melancholic and atypical depression, anger attacks, Axis II disorder, hypersomnia/fatigue, and chronicity of depression. Biological moderator and mediators include cerebral cortical thickness, task-based fMRI (reward and emotion conflict), resting connectivity, diffusion tensor imaging (DTI), arterial spin labeling (ASL), electroencephalograpy (EEG), cortical evoked potentials, and behavioral/cognitive tasks evaluated at baseline and week 1, except DTI, assessed only at baseline. The study is designed to standardize assessment of biomarkers across multiple sites as well as institute replicable quality control methods, and to use advanced data analytic methods to integrate these markers. A Differential Depression Treatment Response Index (DTRI) will be developed. The data, including biological samples (DNA, RNA, and plasma collected before and during treatment), will become available in a public scientific repository.
\end{abstract}

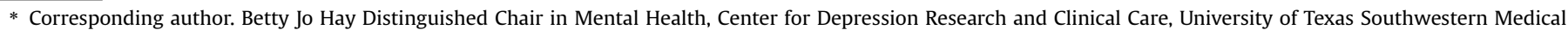
Center, 5323 Harry Hines Blvd. Dallas, TX 75390-9119, USA.

E-mail address: madhukar.trivedi@utsouthwestern.edu (M.H. Trivedi).
} 
Clinical Trial Registration: Establishing Moderators and Biosignatures of Antidepressant Response for Clinical Care for Depression (EMBARC).

Identifier: NCT01407094.

URL: http://clinicaltrials.gov/show/NCT01407094.

(C) 2016 Elsevier Ltd. All rights reserved.

\section{Introduction}

Response to antidepressant medication in depressed patients is unpredictable, with a $30 \%$ remission rate after 12 weeks of treatment; $30-40 \%$ fail to have an adequate response even after several trials of medication or psychotherapy over a year (Fava et al., 2003; Rush et al., 2006; Trivedi et al., 2006). The search for biomarkers predicting overall or specific medication response is still in its infancy (Krishnan and Nestler, 2008). It seems unlikely that a single biomarker based on genetic, neuroimaging, electrophysiology, or clinical presentation will successfully guide treatment selection. Instead, biosignatures - curated combinations of markers with combined predictive value - may be needed.

The NIMH funded multi-site clinical trial Establishing Moderators and Biosignatures of Antidepressant Response in Clinical Care (EMBARC) was designed to systematically explore promising clinical and biological markers of antidepressant treatment outcome and lead to personalized treatment. This paper describes the study rationale and design.

EMBARC is designed to examine both moderating and mediating biomarkers. Moderators, pretreatment variables identifying subgroups with differing treatment effect sizes, predict differential treatment response, and may therefore be used to improve treatment selection. Mediators are variables whose change during treatment, in differing amounts dependent on treatment assignment, is associated with eventual treatment outcome. Mediators can inform decisions to stop ineffective treatment early and may provide insight into underlying physiology of treatment response or toxicity (Trivedi, 2013). The primary aim of EMBARC is to use innovative statistical approaches integrating identified moderators and mediators into a biosignature called the depression treatment response index (DTRI), permitting precision medicine for patients with Major Depressive Disorder (MDD). A secondary aim is to establish standardized procedures for data collection, processing, management, and analyses of multiple complex biological and clinical markers across sites. A healthy control sample provides additional contributions to these aims.

EMBARC is a randomized, placebo-controlled trial of a serotonin selective reuptake inhibitor (SSRI), sertraline, in participants with MDD who are assessed with a comprehensive array of clinical and biological markers of outcome. Participating centers include the University of Texas Southwestern Medical Center (Coordinating Center), Columbia University/Stony Brook (Data Center), Massachusetts General Hospital (MGH), University of Michigan, University of Pittsburgh, and McLean Hospital.

\section{Study design}

EMBARC features a two-stage design. Primary outcomes assessed are symptom reduction (measured using the Hamilton Rating Scale for Depression 17-item [HRSD]) and tolerability (measured with the Frequency, Intensity, and Burden of Side Effects Rating [FIBSER] (Wisniewski et al., 2006)). The target sample is $\mathbf{3 0 0}$ depressed outpatients meeting DSM-IV TR (American Psychiatric Association, 2000) criteria for nonpsychotic MDD. To carefully document each phenotype, individual symptoms, age of onset, number of episodes, and chronicity, all associated with treatment response, are captured in the database (Stewart et al., 1989).

\subsection{Stage 1 treatment phase}

Initially, participants are randomized to an 8-week course of sertraline up to $200 \mathrm{mg}$ daily or placebo (See Fig. 1 for study flow). Medication dose adjustments may occur at weeks 1, 2, 3, 4, and 6 to ensure delivery of appropriate, vigorous, and tolerable pharmacotherapy. At week 8, participants are assessed with the Clinical Global Improvement scale (CGI) and participants who receive a score of less than "much improved" are considered nonresponders. These may be participants who complete 8 weeks with unacceptable/intolerable side effects despite dose reduction, as well as those whose symptom severity does not improve (Please see Fig. 1).

\subsection{Stage 2 treatment phase}

Stage II collects data exploring moderators and mediators of treatment outcome between pharmacologically distinct active treatment arms: sertraline or bupropion, a non-serotonergic antidepressant. Non-responding patients to Stage 1 are crossed over, under double blinded conditions. Sertraline non-responders receive bupropion, and placebo non-responders receive sertraline. Visit frequency, dose escalation, and treatment monitoring follow the same procedures used in Stage 1. The Stage 2 treatment phase permits identification of biosignatures for both second step treatments, as well as a biosignature of treatment resistance to multiple treatments.

\subsection{Healthy control sample}

An additional aim is establishing test-retest reliability (does a given test produce the same result at each administration assuming no change in the subject) and comparability (does a given test produce the same result across sites if administered to the same subject) of all biomarkers in a healthy control sample. The reliability sample is 40 healthy controls; 10 tested at each of the 4 clinical sites. The comparability analyses use a subset of 12 reliability subjects (3/site), who, after testing at their home sites, traveled to and were tested at one additional site. We have completed data collection for this sample.

\section{Selection of clinical markers}

Factors previously reported to have significant even if typically small predictive power for treatment outcome (5-10\% of the variance) were chosen as potential clinical moderators: anxious depression, early life trauma, gender, melancholic and atypical depression, anger attacks, Axis II disorders, hypersomnia/fatigue, and chronicity of depression (Kraemer et al., 2001; Nierenberg, 2003; Rush et al., 2008). For example, STAR*D, the large clinical trial for depression provided clinical information about treatment 


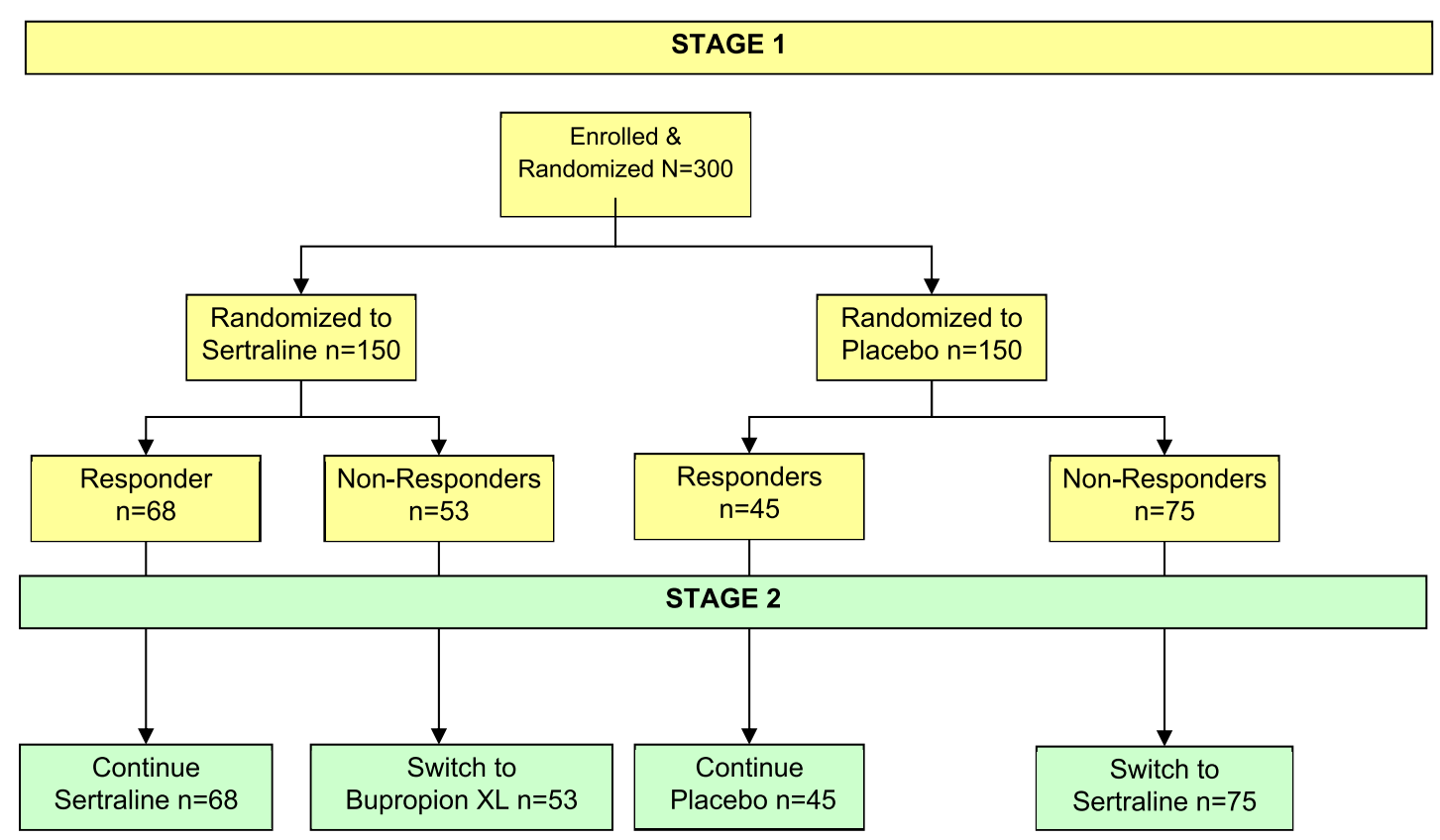

Fig. 1. EMBARC study design.

response during four sequential treatment levels. Comorbid psychiatric and/or medical conditions, greater initial depressive symptom severity, and lower socioeconomic status predicted lower likelihood of remission in response to citalopram (Trivedi et al., 2006; Rush et al., 2008) and so are included as potential moderators.

A number of studies have described anxious depression as a predictor of differential response to treatment. The $46 \%$ of STAR ${ }^{*} \mathrm{D}$ participants with MDD and comorbid anxiety were more likely to suffer increased disease burden and longer illness duration (Fava et al., 2000, 2004). The DSM-V, released May 2013, included a specifier for anxious features, which was added to the EMBARC diagnostic assessment after enrolling approximately 100 patients.

Along with female gender and past or family history of depression, early life trauma is a well-established risk factor for the development of depression. Whether such trauma affects the likelihood of antidepressant response has not been adequately studied. In a post-hoc analysis comparing nefazodone treatment with cognitive behavioral therapy, those with a history of childhood trauma had a better response to psychotherapy, suggesting that it may be a moderator for antidepressant response (Nemeroff et al., 2003).

It should be noted that some of these factors will not change after onset of treatment, and thus can possibly only be moderators However, many clinical markers do change over a course of treatment. For example, comorbid anxiety at baseline may be a moderator, while change in anxiety may be a mediator of treatment. One possibility does not preclude or suggest the other, and baseline anxiety and change in anxiety during treatment are two different markers. See Table 1 for the schedule of all clinical assessments.

\section{Selection of imaging markers}

EMBARC neuroimaging measures are focused on neural circuits modulated by serotonin and dopamine, putatively targeted by sertraline and bupropion, respectively. EMBARC focuses on: 1) serotonin-modulated emotion processing and implicit emotion regulation circuitry centered on the amygdala and medial prefrontal cortex (mPFC) (Etkin et al., 2011; Hariri et al., 2002; Pezawas et al., 2005; Phillips et al., 2008; Surguladze et al., 2012); and 2) dopamine-modulated reward circuitry, centered on ventral striatum (VS) and mPFC (Haber and Knutson, 2010; Schultz, 2007). Several studies have implicated functional abnormalities in these circuits in MDD (Almeida et al., 2009; Fu et al., 2004; Harvey et al., 2007; Heller et al., 2009; Knutson et al., 2008; Kumar et al., 2008; Robertson et al., 2007; Ruhe et al., 2012; Sheline et al., 2001; Suslow et al., 2010; Victor et al., 2010).

Baseline neuroimaging measures of function in these circuits may predict treatment response. Specifically, there is an association between the magnitude of pre-treatment metabolism in the MPFC and subsequent response to antidepressant medication (predominantly SSRIs) in individuals with MDD (Pizzagalli, 2011). Almost no studies have examined the extent to which neuroimaging measures of function in reward circuitry predict response to antidepressant medications; this is a significant goal of EMARC neuroimaging.

MDD is associated with gray matter, white matter, and resting state functional abnormalities in amygdala-mPFC circuitry (Anand et al., 2005; Campbell et al., 2004; Dalby et al., 2010; Jarnum et al., 2011; Koolschijn et al., 2009; Peterson et al., 2009; Sheline et al., 2010). Neuroimaging modalities targeting these areas have provided evidence that their levels of activity may predict antidepressant response. For example, one study of late-life depression reported that response to sertraline was associated with lower fractional anisotropy (FA), a measure of the density of collinear fibers, in prefrontal cortex white matter (Taylor et al., 2008). Another study found remitters to escitalopram had lower FA in the left superior-temporal white matter compared with non-remitters, and that lower cortical thickness in several regions, most prominently in the left lateral-orbital cortex, predicted remission (Parsey R, personal communication 09/03/2013). Another study reported increased perfusion in several regions, including right ventral mPFC, in MDD responders versus non-responders to at least two antidepressant medications (Lui et al., 2009; McGrath et al., 2013).

In EMBARC, we employ two well-validated fMRI paradigms to respectively examine two relevant neural circuits. First, an 
Table 1

Schedule of assessments - treatment phase.

\begin{tabular}{|c|c|c|c|c|c|c|c|c|c|c|c|c|c|c|}
\hline \multirow[t]{4}{*}{ Rating or procedure } & \multicolumn{14}{|c|}{ Schedule of assessments - Treatment phase } \\
\hline & \multicolumn{14}{|c|}{ Study visit } \\
\hline & \multicolumn{3}{|c|}{ Prior to randomization } & \multicolumn{11}{|c|}{ Study week } \\
\hline & Evaluation & Biological markers & Randomization (baseline) & 1 & 2 & 3 & 4 & 6 & 8 & $9^{a}$ & 10 & 12 & 14 & 16 \\
\hline Consent & $\mathrm{X}$ & & & & & & & & & & & & & \\
\hline Eligibility for enrollment & $\mathrm{X}$ & & & & & & & & & & & & & \\
\hline Demographics & $\mathrm{X}$ & & & & & & & & & & & & & \\
\hline SCID-I & $\mathrm{X}$ & & & & & & & & & & & & & \\
\hline ATRQ & $\mathrm{X}$ & & & & & & & & & & & & & \\
\hline Metal screen & $\mathrm{X}$ & & & & & & & & & & & & & \\
\hline EHI & $\mathrm{X}$ & & & & & & & & & & & & & \\
\hline Labs & $\mathrm{X}$ & & & & & & & & & & & & & \\
\hline Physical exam & $\mathrm{X}$ & & & & & & & & & & & & & \\
\hline HT/WT/BMI/WAIST & $\mathrm{X}$ & & & & & & & & & & & & & \\
\hline $\mathrm{BP}$ & $\mathrm{X}$ & & & & & & & & $\mathrm{X}$ & $\mathrm{X}$ & $\mathrm{X}$ & $\mathrm{X}$ & $\mathrm{X}$ & $\mathrm{X}$ \\
\hline EEG/Behavioral & & $\mathrm{X}$ & & $\mathrm{X}$ & & & & & & & & & & \\
\hline SSAI & & $\mathrm{X}$ & & $\mathrm{X}$ & & & & & & & & & & \\
\hline Vams & & $\mathrm{X}$ & & $\mathrm{X}$ & & & & & & & & & & \\
\hline Fagerstrom & & $\mathrm{X}$ & & $\mathrm{X}$ & & & & & & & & & & \\
\hline Resting EEG & & $\mathrm{X}$ & & $\mathrm{X}$ & & & & & & & & & & \\
\hline Evoked potential & & $\mathrm{X}$ & & $\mathrm{X}$ & & & & & & & & & & \\
\hline Word fluency & & $\mathrm{X}$ & & $\mathrm{X}$ & & & & & & & & & & \\
\hline Flanker task & & $\mathrm{X}$ & & $\mathrm{X}$ & & & & & & & & & & \\
\hline A not B task & & $\mathrm{X}$ & & $\mathrm{X}$ & & & & & & & & & & \\
\hline Choice reaction & & $\mathrm{X}$ & & $\mathrm{X}$ & & & & & & & & & & \\
\hline Probablistic reward & & $\mathrm{X}$ & & $\mathrm{X}$ & & & & & & & & & & \\
\hline MRI & & $\mathrm{X}$ & & $\mathrm{X}$ & & & & & & & & & & \\
\hline SSAI & & $\mathrm{x}$ & & $\mathrm{X}$ & & & & & & & & & & \\
\hline MASQ & & $\mathrm{X}$ & & $\mathrm{X}$ & & & & & & & & & & \\
\hline SHAPS & & $\mathrm{X}$ & & $\mathrm{X}$ & & & & & & & & & & \\
\hline Visual acuity & & $\mathrm{X}$ & & $\mathrm{X}$ & & & & & & & & & & \\
\hline Bold & & $\mathrm{X}$ & & $\mathrm{X}$ & & & & & & & & & & \\
\hline ASL & & $\mathrm{X}$ & & $\mathrm{X}$ & & & & & & & & & & \\
\hline Emotional Recog & & $\mathrm{X}$ & & $\mathrm{X}$ & & & & & & & & & & \\
\hline Reward task & & $\mathrm{X}$ & & $\mathrm{X}$ & & & & & & & & & & \\
\hline Structural imaging & & $\mathrm{X}$ & & $\mathrm{X}$ & & & & & & & & & & \\
\hline Blood collection & & $\mathrm{X}$ & & $\mathrm{X}$ & & & $\mathrm{X}$ & & $\mathrm{X}$ & $\mathrm{X}$ & & $\mathrm{X}$ & & $\mathrm{X}$ \\
\hline QIDS-SR & $\mathrm{X}$ & $\mathrm{X}$ & $\mathrm{X}$ & & & & & & & & & & & \\
\hline Eligibility for randomization & & & $\mathrm{X}$ & & & & & & & & & & & \\
\hline FHS & & & $\mathrm{X}$ & & & & & & & & & & & \\
\hline SCQ & & & $\mathrm{X}$ & & & & & & & & & & & \\
\hline AAQ & & & $\mathrm{X}$ & & & & & & & & & & & \\
\hline MDQ & & & $\mathrm{X}$ & & & & & & & & & & & \\
\hline CTQ & & & $\mathrm{X}$ & & & & & & & & & & & \\
\hline NEO-FFI & & & $\mathrm{X}$ & & & & & & & & & & & \\
\hline SAPAS & & & $\mathrm{X}$ & & & & & & & & & & & \\
\hline WASI & $\mathrm{X}$ & & & & & & & & & & & & & \\
\hline HRSD & & & $\mathrm{X}$ & $\mathrm{X}$ & $\mathrm{X}$ & $\mathrm{X}$ & $\mathrm{X}$ & $\mathrm{X}$ & $\mathrm{X}$ & $\mathrm{X}$ & $\mathrm{X}$ & $\mathrm{X}$ & $\mathrm{X}$ & $\mathrm{X}$ \\
\hline CGI & & & & & & & & & $\mathrm{X}$ & & & & & \\
\hline SAS & & & $\mathrm{X}$ & & & & $\mathrm{X}$ & & $\mathrm{X}$ & & & $\mathrm{X}$ & & $\mathrm{X}$ \\
\hline PFIB & & & $\mathrm{X}$ & $\mathrm{X}$ & $\mathrm{X}$ & $\mathrm{X}$ & $\mathrm{X}$ & $\mathrm{X}$ & $\mathrm{X}$ & $\mathrm{X}$ & $\mathrm{X}$ & $\mathrm{X}$ & $\mathrm{X}$ & $\mathrm{X}$ \\
\hline TESS & & & & $\mathrm{X}$ & $\mathrm{X}$ & $\mathrm{X}$ & $\mathrm{X}$ & $\mathrm{X}$ & $\mathrm{X}$ & $\mathrm{X}$ & $\mathrm{X}$ & $\mathrm{X}$ & $\mathrm{X}$ & $\mathrm{X}$ \\
\hline FIBSER & & & & $\mathrm{X}$ & $\mathrm{X}$ & $\mathrm{X}$ & $\mathrm{X}$ & $\mathrm{X}$ & $\mathrm{X}$ & $\mathrm{X}$ & $\mathrm{X}$ & $\mathrm{X}$ & $\mathrm{X}$ & $\mathrm{X}$ \\
\hline CHRT $( \pm \text { C-SSRS })^{b}$ & & & $\mathrm{X}$ & $\mathrm{X}$ & $\mathrm{X}$ & $\mathrm{X}$ & $\mathrm{X}$ & $\mathrm{X}$ & $\mathrm{X}$ & $\mathrm{X}$ & $\mathrm{x}$ & $\mathrm{X}$ & $\mathrm{X}$ & $\mathrm{X}$ \\
\hline SFI & & & $\mathrm{X}$ & & & & $\mathrm{X}$ & & $\mathrm{X}$ & & & $\mathrm{X}$ & & $\mathrm{X}$ \\
\hline ASRM & & & $\mathrm{X}$ & & & & $\mathrm{X}$ & & $\mathrm{X}$ & & & $\mathrm{X}$ & & $\mathrm{X}$ \\
\hline CAST & & & $\mathrm{X}$ & $\mathrm{X}$ & $\mathrm{X}$ & $\mathrm{X}$ & $\mathrm{X}$ & $\mathrm{X}$ & $\mathrm{X}$ & $\mathrm{X}$ & $\mathrm{X}$ & $\mathrm{X}$ & $\mathrm{X}$ & $\mathrm{X}$ \\
\hline PAQ & & & & $\mathrm{X}$ & $\mathrm{X}$ & $\mathrm{X}$ & $\mathrm{X}$ & $\mathrm{X}$ & $\mathrm{X}$ & $\mathrm{X}$ & $\mathrm{X}$ & $\mathrm{X}$ & $\mathrm{X}$ & $\mathrm{X}$ \\
\hline Time (minutes) & 150 & 250 & 70 & 280 & 45 & 30 & 40 & 30 & 50 & 40 & 35 & 45 & 35 & 50 \\
\hline
\end{tabular}

a An additional visit is scheduled at Week 9 only for participant's crossing over to an alternative treatment.

b The C-SSRS will be completed only for participants scoring positive on a suicide item of the CHRT. Altman Self-Rating Mania Scale (ASRM); Anger Attacks Questionnaire

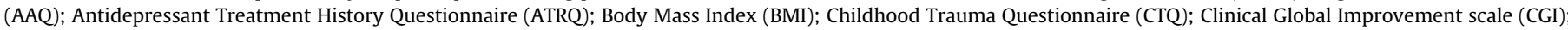

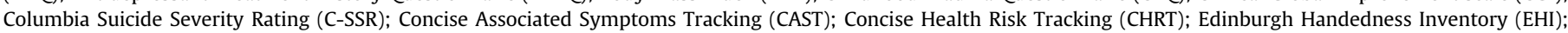

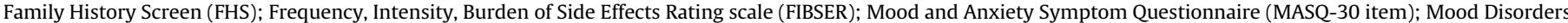

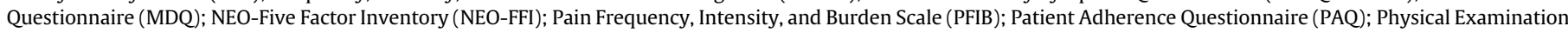

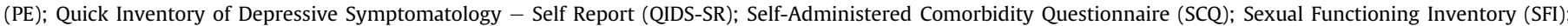

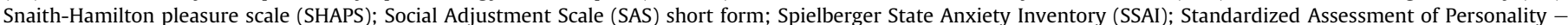

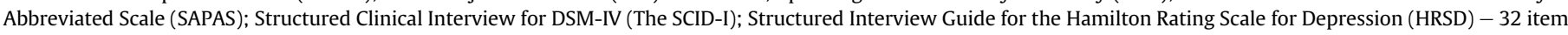
$\left(\mathrm{SIGH}-\mathrm{D}_{32}\right)$; Treatment Emergent Signs and Symptoms (TESS); Visual Analogue of Mood Scales (VAMS); Wechsler Abbreviated Scale of Intelligence (WASI).

emotional conflict task that reliably activates serotonin-modulated amygdala-ACC/mPFC circuitry during implicit emotion regulation
(Etkin et al., 2006); Second, a reward processing task that activates dopamine-modulated striatal and mPFC circuitry during 
anticipation and receipt gains or losses (Forbes et al., 2010a, 2010b). The first aim is to identify pretreatment moderators of emotion processing and implicit emotion regulation that predict differential response to sertraline versus placebo. We also will examine pretreatment reward circuitry function and structure for moderators of differential response to bupropion versus sertraline in Stage 2. The second aim is to identify changes in the above measures of function in these two key neural circuits measured pre-treatment and after one week of treatment that mediate differential response to sertraline and placebo in Stage 1, and to bupropion and sertraline in Stage 2. We will also attempt to identify patterns of activity in non-responders to sertraline in Stage 1 that moderate differential response to bupropion versus sertraline in Stage 2. We will also examine the extent to which measures of resting state functional connectivity, resting perfusion, gray and white matter volumes and cortical thickness at baseline act as moderators and changes in the functional act as mediators of differential treatment response throughout the study. Non-responders to both Stage 1 and 2 will provide a biosignature of treatment resistance.

\section{Selection of electrophysiology markers}

Pre-treatment EEG measures in alpha and theta bands have been repeatedly associated with antidepressant response (Bruder et al., 2013). Specifically, higher posterior alpha power differentiates patients who respond to antidepressants from those who do not (Bruder et al., 2008; Tenke et al., 2011; Ulrich et al., 1986). Furthermore, compelling evidence highlights a significant association between higher pre-treatment resting theta EEG activity in the rostral ACC and antidepressant response (including to SSRIs) (Korb et al., 2009; Mulert et al., 2007; Pizzagalli et al., 2001; Rentzsch et al., 2014). A recent meta-analysis found that the correlation between pre-treatment rostral ACC activity and antidepressant response has been replicated 19 times (Pizzagalli, 2011). Moreover, prior studies have shown that patients with higher pretreatment loudness-dependence of auditory evoked potentials (LDAEP), assumed to reflect blunted serotonergic activity, responded well to SSRI, while responders to the selective noradrenergic reuptake inhibitor, reboxetine, had low pretreatment LDAEP (Mulert et al., 2007). Similarly, response to citalopram was associated with strong LDAEP (Linka et al., 2004), while response to reboxetine was associated with weak LDAEP (Linka et al., 2005). Thus, EMBARC will test whether pre-treatment resting EEG alpha or theta measures and LDAEP moderate response to an SSRI.

\section{Selection of behavioral and cognitive tasks}

\subsection{Reaction times}

Interference and post-error adjustments are measured during performance of the implicit emotion processing and regulation and reward processing neuroimaging tasks as key behavioral measures associated with ACC and ventral striatal-centered neural circuitry that, in turn, have potential to be useful pre-treatment signatures moderating treatment response. Other moderators include measures of psychomotor slowing, cognitive control and working memory (Gorlyn et al., 2008; Julian and Mohr, 2006; Taylor et al., 2006), and reward responsiveness (Pizzagalli et al., 2008).

\subsection{Psychomotor slowing}

Psychomotor slowing is a specific predictor of SSRI treatment non-response (Caligiuri et al., 2003; Flament et al., 1999; Kalayam and Alexopoulos, 1999; Taylor et al., 2006). Using a brief word fluency task (the Controlled Oral Word Association Test), Taylor et al. (2006) reported that psychomotor slowing was the strongest predictor of fluoxetine non-response 12 weeks later. Interestingly, low pre-treatment psychomotor speed predicted better response to an 8-week treatment with bupropion-sustained release in MDD outpatients (Herrera-Guzman et al., 2008). These findings suggest pre-treatment psychomotor slowing might moderate response.

\subsection{Cognitive control}

Studies from Pizzagalli's laboratory have found abnormal reactions to errors in dysphoric subjects (Pizzagalli et al., 2006), unmedicated subjects with MDD (Holmes and Pizzagalli, 2008), and psychiatrically healthy individuals genetically at increased depression risk (Holmes et al., 2010). In each group, abnormal error reaction was associated with dysfunctional activity in the rACC. Importantly, among controls, resting rACC activity predicted posterror behavioral adjustments during a flanker task (Pizzagalli et al., 2006). Based on these findings, EMBARC tests whether post-error behavioral adjustments in the flanker task might moderate response to treatment.

\subsection{Working memory}

Global deficits on neuropsychological tests have been found to predict poor response to SSRIs, with deficits in working memory being most predictive (Gorlyn et al., 2008). Moreover, performance on working memory tasks that require manipulation of information improved following SSRI treatment (Herrera-Guzman et al., 2009). Thus, EMBARC examines whether performance on the A NOT B working memory task may moderate treatment response.

\subsection{Reward learning}

In EMBARC, we are investigating a core behavioral component of anhedonia - reward learning - assessed objectively using a probabilistic reward task. Critically, performance on this task has been found to 1 ) be modulated by dopaminergic compounds (Pizzagalli et al., 2008) and 2) correlate with activation in rewardrelated striatal regions (Santesso et al., 2008). Based on these findings, EMBARC will examine reward learning as a possible moderator of treatment response.

\section{Selection of genetic and other blood based markers}

An integrated approach to developing biosignatures for therapeutic targets in the rapidly developing field of neuropsychopharmacology requires use of the latest methods and a highly specialized understanding (Emmett et al., 2014). Therefore, biospecimens from EMBARC will be collected and made available for the scientific community (Uher et al., 2009). DNA, mRNA, and plasma are collected in all participants at baseline, and weeks 1, 8, 9 (for nonresponders), and 16. Immortalized cell lines are also raised from leukocyte samples collected at baseline. The biospecimens have been placed in the National Institute for Mental Health (NIMH) repository at Rutgers University (http://nimhgenetics.org) and will be usable for integrated biological approaches such as proteomics, metabolomics, etc.

Table 2 lists the planned EMBARC moderators and mediators.

\section{Study aims: development of a differential treatment response index (DTRI)}

EMBARC includes multiple biomarkers with the aim of developing a biosignature called the DTRI, similar in concept to the 
Table 2

EMBARC moderators and mediators.

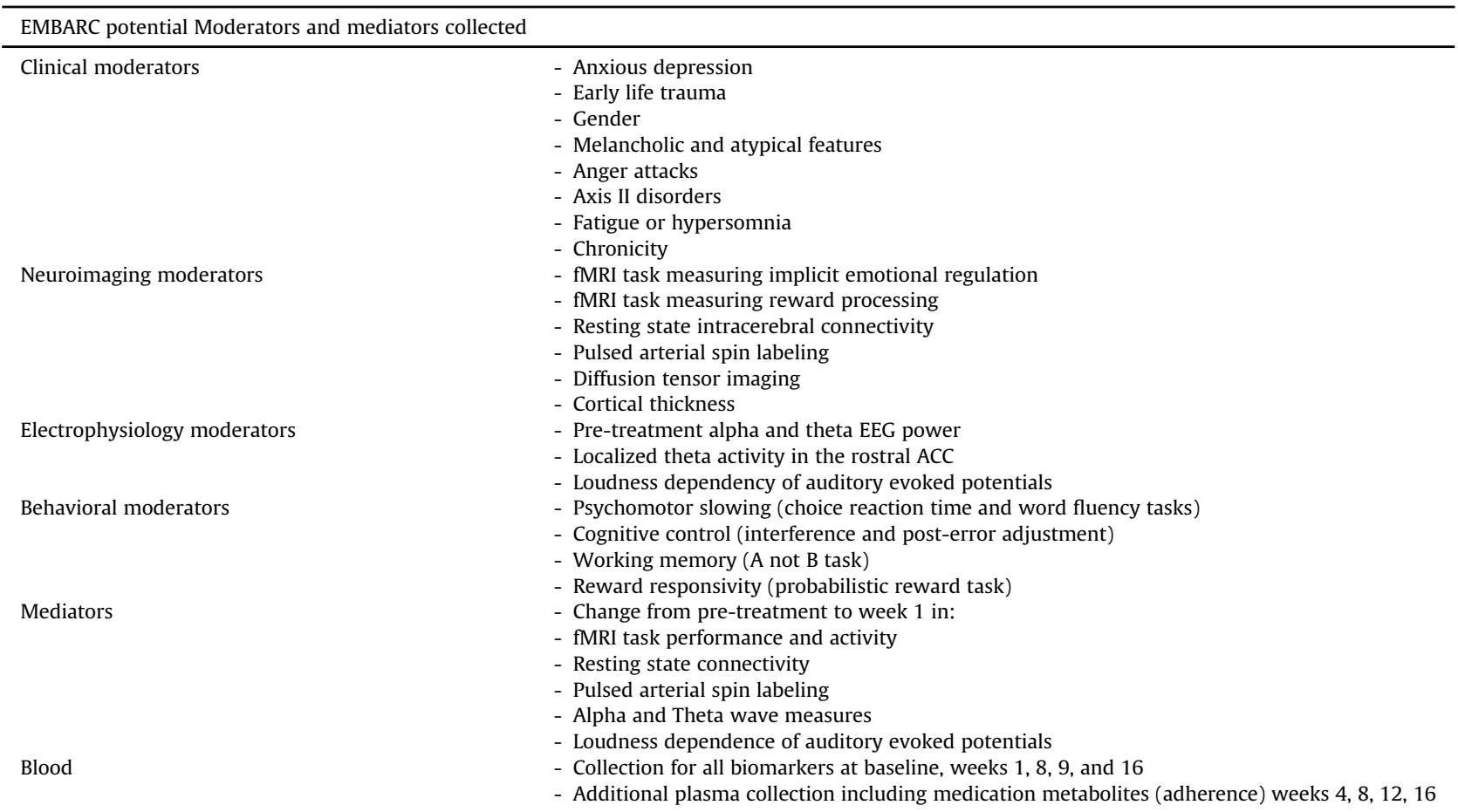

Framingham Risk score for cardiac risk. The DTRI is intended to permit personalization of treatment by incorporating multiple moderators - maximizing both symptom reduction and treatment tolerability. Sub-aims in constructing the DTRI include the identification of individual clinical, neuroimaging, electrophysiological and behavioral markers that moderated differential outcome (sertraline vs. placebo) considering both tolerability and response. Similarly, mediator variables in each of these areas (see Table 2) will be analyzed for differential predicative ability. The concept of DTRI will also be extended to the phase II outcomes and compare the second stage treatments in those who failed to respond in phase I.

Additionally, EMBARC will examine more traditional study aims, using remission on the HDRS (exit score $\leq 7$ ) to compare the effectiveness of sertraline vs. placebo and sertraline vs. bupropion. EMBARC also aims to extend clinical trials methodology through the development of a scale measuring treatment acceptability and examining the role that this concept plays in outcome. Finally, the methodology used to develop the DTRI is intended to advance statistical analysis of biosignature trials (see below) through comparison of existing methods and development of new methods of predicting outcome.

\section{Study participants}

This trial is conducted according to the FDA guidelines and the Declaration of Helsinki and approved by Institutional Review Board at each clinical site. Signed informed consent and agreement to all procedures is obtained from all participants at study entry. Outpatients age 18-65 with MDD, diagnosed by the use of the Structured Clinical Interview for DSM-IV Axis I Disorders (SCID) are recruited at four university sites. Table 1 describes assessments and their timing. Subjects must meet SCID criterion for an MDD episode and have a Quick Inventory of Depressive Symptomatology score (QIDS-SR) of $\geq 14$ at both screening and randomization visits. To reduce heterogeneity, only patients with early onset (before age 30 ), chronicity (episode duration $>2$ years) or recurrent MDD (two or more recurrences including current episode) are enrolled. Early onset has been associated with increased familial loading (Levinson et al., 2007; Weissman et al., 1984).

In addition, all patients must have not failed to respond to any prior trial of an antidepressant in the current episode at an adequate dose and duration, as defined by the MGH Antidepressant Treatment Response Questionnaire (MGH-ATRQ) (Chandler et al. 2010). Additional exclusion criteria include: 1) current pregnancy, fertile but not using contraception, or breastfeeding, 2) lifetime history of psychosis or bipolar disorder, 3) meeting DSM-IV criteria for substance dependence in the past 6 months or substance abuse in the past 2 months, 4) unstable psychiatric or general medical conditions that may require hospitalization or contraindicate study medication, 5) clinically significant laboratory abnormalities, 6) history of epilepsy or condition requiring an anticonvulsant, 7) treatment with ECT, VNS, rTMS or other somatic treatments in the current episode, 8) protocol excluded medications (including but not limited to antipsychotics, and mood stabilizers), 9) current depression-specific psychotherapy, and 10) considered by study investigator to be a significant suicide risk.

\section{Study drug dosing}

In EMBARC, study drug is titrated using a standardized protocol accounting for tolerability. All medication is administered as a single daily dose of matched capsules in a double dummy design. The target dose is the maximum dose ( $450 \mathrm{mgs}$ for bupropion XL and $200 \mathrm{mgs}$ for sertraline) in participants who tolerate the medication but have not responded, or the highest tolerable dose. Participants who do not meet response criteria during Stage 1 treatment will be crossed over, double-masked, from placebo to sertraline or from sertraline to bupropion XL for eight weeks, with all ratings collected at the equivalent time points during phase II as in phase I. Participants unable to tolerate Stage 1 treatment may exit the study. 


\section{Concomitant medications}

Any treatment for any general medical condition is allowed. Study clinicians are trained to recognize non-protocol medications (e.g., Type 1C antiarrhythmics, beta blockers, etc.) for which serum levels or dose adjustments may be needed. Medications to treat antidepressant medication side effects (i.e., anxiety/agitation, insomnia, and sexual dysfunction) are allowed. All concomitant medications are recorded at each study visit.

\section{Data management}

All clinical data, biosignatures assessments, and biospecimen data are stored in the StudyTRAX electronic data management system customized for this study. StudyTRAX is a Clinical Trials Management Software sold by Science TRAX, LLC. StudyTRAX uses a Microsoft SQL server backend database with an internet browser based interface. It is HIPAA compliant with transmission security, 21 CFR Part 11 compliance, audit trails, electronic signatures, user authentication, study, site, and role-based security and can create de-identified datasets. The system supports electronic data capture allowing data to be entered directly into the browser with no intermediate recording.

\section{Analytic strategy}

EMBARC is designed to discover patient characteristics that can guide treatment for individual patients. In contrast to traditional scientific practice, where hypotheses are formulated before examination of the data or even before the conduct of a study, discovery studies identify previously unknown relationships through rigorous and systematic exploration of data, employing the most appropriate statistical methods. Formally, a treatment regime is a rule that assigns a treatment from among a set of possible treatments, to a patient based on her/his characteristics. Estimating the optimal individual treatment regime using data from a clinical trial or an observational study is currently the subject of active research (Gunter et al., 2011; Henderson et al., 2010; Murphy, 2003; Robins et al., 2008; Wallace et al., 2013; Zhao et al., 2012). We plan to employ several different existing techniques and to develop new statistical methods for EMBARC. Here we outline some strategies that will be employed.

A number of measures of treatment outcome will be considered including: 1) response at exit (HRSD score reduction of $50 \%$ or greater), a binary measure likely (on theoretical grounds) to yield minimal power and precision; 2) time to remission (for which survival methods could be used), likely to yield slightly greater power and precision; 3) repeated HRSD scores, likely to give greatest power and precision. Very little is known about whether using such varying outcome measures will yield concordant results, and how much power or precision is sacrificed in using a less sensitive outcome measure. Investigating these factors is a significant goal of EMBARC.

In order to validate the DTRI, the sample will be divided into two: 1) a randomly selected two-thirds for model development, and 2) the remaining one-third for testing the final model. Crossvalidation will be used throughout the model development stage.

\section{Moderators of treatment effect}

The initial development of a DTRI will focus on moderators rather than mediators because if there are strong moderators, relevant mediators may differ in the subgroups defined by the moderators. The primary approach to identifying moderators and combining them into a DTRI consists of three phases. In the first phase, we will examine and rank pre-specified baseline characteristics as potential moderators of treatment response. The goal of the second phase is to discover new moderators. Finally, the goal of the third phase is to identify combinations of moderators that are superior to the individual moderators identified in phases 1 and 2.

\subsection{Examine and rank pre-specified moderators of treatment response}

Classically, individual baseline characteristics are assessed as potential treatment moderators using a linear model to predict treatment outcome as a function of site, treatment, treatment by site interaction, the baseline patient characteristic of interest $(\mathrm{M})$, and the interactions of $\mathrm{M}$ with the other factors. Inclusion of sideeffects are necessitated by the multi-site design, and within this framework it is possible to test the homogeneity of effect sizes over sites. If site-heterogeneity in effect sizes is identified, an effort will be made to locate the source of such heterogeneity. The treatment by $\mathrm{M}$ and the treatment by $\mathrm{M}$ by site interactions are also relevant to moderators. If there is no three-way interaction, the common moderator effect size can be estimated in terms of the treatment by $\mathrm{M}$ interaction; otherwise, this interaction describes the average moderator effect size over sites.

We will consider 1) logistic regression models for binary outcomes such as response at exit, 2) Cox Proportional Hazards models for survival outcomes such as time to remission, and 3) hierarchical linear models for continuous longitudinal outcomes such as HRSD ratings. Within the linear model framework, moderators may be ranked based on measured effect size as proposed by Kraemer (Kraemer, 2013). Briefly, a moderator effect size is computed by taking all possible pairs of participants, one from each treatment arm, and computing the product moment correlation between the outcome difference between the two participants and the average of the standardized moderator for each pair. This correlation coefficient is the population parameter tested by the treatment $\mathrm{X}$ moderator interaction, and its magnitude relates to the strength of moderation of M on treatment outcome (Kraemer, 2013). This effect size measure is a number between -1 and +1 with a value of zero when there is no moderator effect and can be used to rank order the proposed moderators for each treatment outcome.

The relationship between a baseline characteristic and treatment outcome may not be linear, and other assumptions of the linear model might not be satisfied. To address this, the definition of a treatment effect moderator can be generalized to the case where smooth functions representing the relationships in the two treatment groups are not parallel and when normality assumptions are not satisfied. We are currently extending the parametric linear model methodology to evaluate moderators of treatment and developing methods for quantifying differences between treatment curves, which would permit ranking moderators even when parametric assumptions are not satisfied.

\subsection{Identify new moderators of treatment response}

The above approaches are used for individual characteristics that are scalar, but many patient characteristics are complex data objects such as images or time series. For example, EEG recordings result in a time series for each electrode, which is a 1-dimensional data object, while fMRI data are technically 4-dimensional (3dimensions plus time) objects, they will be reduced to 3dimensions for the purpose of moderator identification. Based on previous findings, participants' biological characteristics (which are 2-, or 3-dimensional data objects, e.g. images) can be reduced to scalar aggregates. These aggregates typically are the average value of the characteristic over the entire image or the average over a 
specific region of interest (ROI). However, in this phase of the analysis we attempt to identify new moderators of treatment effect by using the entire image as a predictor. While machine learningtype algorithms are powerful predictive engines (Marquand et al., 2008; Mitchell et al., 2004; Mourao-Miranda et al., 2005; Sato et al., 2009), casting the problem in terms of a statistical model permits formulation of hypotheses about moderation of treatment effect and allows use of well-developed principles for calculating confidence intervals/confidence bands, hypothesis testing, etc. Further, the results of such an analysis tend to be more interpretable, as they respect the functional structure of the data (in this case intrinsic brain architecture), while the data structure is ignored in the former approach. Progress has been made (James et al., 2009; Reiss and Ogden, 2010) and efforts to develop efficient methods for facilitating analysis during this phase continue.

\subsection{Combining measures to obtain a "best" moderator of treatment effect}

The ranking individual moderators may shed light on underlying contributors to the magnitude of treatment effect for a given patient and contribute to hypotheses regarding the antidepressant mechanisms of action. However, based on past experience, no one moderator is likely to be strong enough to affect clinical decision making by itself; one might have to combine several factors to accomplish this. Thus several established and new approaches to combining measures to obtain a (non-unique) "best" moderator will be considered. One approach developed by Wallace et al. (2013) involves a multiple regression model (Wallace et al., 2013). The dependent variable is the treatment outcome difference for all possible pairs of subjects across treatment arms and there is an independent variable of the moderator averages for these pairs for each possible moderator. The model coefficients are used to compute a moderator score for each participant. This approach has been used successfully in an exploratory study (Wallace et al., 2012) comparing drug (SSRI) to psychotherapy for patients with MDD. Multiple measures (largely non-biological) were examined as possible moderators of treatment outcome and eight - some individually weak - were identified and combined into a strong moderator.

EMBARC will also investigate the suitability of some wellestablished statistical modeling approaches, such as tree-based methods and penalization methods, for constructing a DTRI. In the first approach, a recursive partitioning algorithm will use prespecified potential moderators to classify subjects by treatment outcome (e.g., remission at exit). The resulting decision tree will be translated into a nominal variable, which will in turn be used as the only predictor of treatment outcome in a logistic regression model. Here, the DTRI for a future subject is the probability of a positive treatment outcome determined by the model.

In the second approach, a logistic regression model of treatment outcome will be constructed for each treatment group using the pre-specified potential moderators. Methods such as ridge regression, the lasso, and the elastic net will be used to develop the model using techniques such as principal components analysis to reduce the number of independent variables. A future subject will be assigned the treatment with the highest predicted probability of a positive outcome.

\section{Mediators of treatment effect}

An analytic strategy similar to the one described above for discovering moderators of treatment effect will be employed for the discovery of mediators of treatment effect. However, instead of examining baseline patient characteristics, changes in characteristics from baseline to the second assessment occurring at 1 week post-treatment will be the focus. The first step in mediator analysis will be to examine which of the proposed mediators are correlated with treatment choice. For this first step, the effect size here is simply the treatment effect on the proposed mediator. The stronger the effect of treatment on the proposed mediator, the greater is the potential mediator effect size. Thus, many proposed mediators will be eliminated from consideration simply because they are not differentially affected by choice of treatment. Thereafter, the parametric analytic model is exactly the same as that for moderation. However, while the criterion to establish moderation requires a significant interaction of treatment by $M$, either a main effect of $M$ or an interaction effect is sufficient to establish mediation.

\section{Resource sharing plan}

The EMBARC biomarker data and biomaterials constitute a national scientific resource and will be made available to the research community six months after the final study visit. Well-documented de-identified dataset(s), will include all data obtained in the course of the study and will be publically available. These datasets will comport with National Institute for Mental Health (NIMH) guidelines for organization, documentation, and preservation of participant privacy. The clinical datasets will reside with the biomarker datasets through existing databases (e.g. http://ndg.sfn.org/ eavXSearch.aspx? $\mathrm{db}=10 \& \mathrm{cl}=81$ ). Biospecimens will be available through the NIMH Human Genetics Initiative at Rutgers University. The repository is responsible for distributing data, as directed by EMBARC principle investigators, to other qualified investigators. All data will de-identified and consent forms reflect these procedures and allow for repository use (see http://embarc.utsouthwestern. edu).

\section{Baseline characteristics}

Recruitment for EMBARC began in August 2011, and completed in December 2015. A total of 677 participants were screened, and 309 were randomized in the clinical trial (including 10 who were enrolled in the feasibility trial). In addition, 40 healthy controls participated. Among participants with MDD who were randomized, $57 \%$ were female, the majority (65\%) were Caucasian, and mean age was 37.3 years $( \pm 13.2)$. Depression severity ranged from moderate to severe based on the HAM-D and QIDS-SR. Tables 3 and 4 provide the baseline demographic and clinical characteristics of the sample. Completion rate for imaging, EEG assessments, and behavioral phenotyping was remarkably high at baseline and week 1 (Table 5).

\section{Discussion}

The problems of developing personalized medicine relate not only to the specific situation addressed in EMBARC, but also to treatments for all mental and even physical disorders. Consequently, what is learned in EMBARC may provide guidance for many future studies. Defining the population of interest is crucial, since the results of a study apply directly only to that population. The population, to the extent possible, should be heterogeneous in terms of treatment effectiveness, including all those for whom the choice between particular treatments is relevant for clinicians, excluding those unwilling to participate or for whom participation imposes a risk. The sample must be large enough to yield reasonably precise estimates effect sizes, as well as sufficient information to design powerful yet cost-effective studies testing the moderators/mediators detected. Sharing data, once the study is done, facilitates such subsequent testing, and it is likely that EMBARC, and 
Table 3

Baseline demographic characteristics $(\mathrm{n}=309)$.

\begin{tabular}{|c|c|c|c|}
\hline & Mean & SD & Percent \\
\hline Age & 37.31 & 13.24 & \\
\hline Sex: Female & & & $57 \%$ \\
\hline \multicolumn{4}{|l|}{ Race } \\
\hline White & & & $65 \%$ \\
\hline African American & & & $19 \%$ \\
\hline Other & & & $16 \%$ \\
\hline Hispanic ethnicity & & & $19 \%$ \\
\hline \multicolumn{4}{|l|}{ Marital status } \\
\hline Married & & & $20 \%$ \\
\hline Partnered & & & $1 \%$ \\
\hline Single & & & $60 \%$ \\
\hline Divorced & & & $16 \%$ \\
\hline Separated & & & $2 \%$ \\
\hline Widowed & & & $1 \%$ \\
\hline \multicolumn{4}{|l|}{ Employment status } \\
\hline Full time & & & $32 \%$ \\
\hline Part time & & & $23 \%$ \\
\hline Unemployed & & & $43 \%$ \\
\hline Education (years) & 15.01 & 2.61 & \\
\hline Number in household & 2.43 & 1.72 & \\
\hline House monthly income & $\$ 4696$ & $\$ 15,828$ & \\
\hline
\end{tabular}

Table 4

Baseline clinical characteristics $(\mathrm{n}=309)$.

\begin{tabular}{|c|c|c|}
\hline & Mean & SD \\
\hline Age of onset (first MDE) & 14.51 & 8.15 \\
\hline Duration of current episode (months) & 40.22 & 69.91 \\
\hline \multicolumn{3}{|l|}{ Family history: first degree relatives with } \\
\hline Serious mental illness & 1.09 & 1.46 \\
\hline Feeling sad or blue & 1.37 & 1.55 \\
\hline Attempted suicide & 0.20 & 0.53 \\
\hline Altman self-rating mania scale & 1.49 & 1.89 \\
\hline Anger attack questionnaire & 0.38 & 0.49 \\
\hline \multicolumn{3}{|l|}{ Childhood trauma questionnaire } \\
\hline Emotional neglect & 13.50 & 5.01 \\
\hline Emotional abuse & 13.16 & 5.77 \\
\hline Physical neglect & 8.40 & 3.64 \\
\hline Physical abuse & 8.64 & 4.56 \\
\hline Sexual abuse & 8.35 & 5.74 \\
\hline Validity & 6.87 & 3.09 \\
\hline CGI baseline (global severity) & 4.35 & 0.67 \\
\hline \multicolumn{3}{|l|}{ Columbia suicide severity rating } \\
\hline Baseline intensity score & 14.61 & 5.24 \\
\hline Concise associated symptoms tracking scale total score & 30.42 & 8.97 \\
\hline Risk score & 5.39 & 2.34 \\
\hline Propensity score & 26.5 & 8.27 \\
\hline $\mathrm{HRSD}_{17}$ & 18.67 & 4.42 \\
\hline $\mathrm{HRSD}_{32}$ & 26.22 & 5.7 \\
\hline Social adjustment scale & 2.59 & 0.57 \\
\hline \multicolumn{3}{|l|}{ Snaith-Hamilton pleasure scale } \\
\hline Sum of dichotomous (0/1) split & 5.62 & 3.5 \\
\hline \multicolumn{3}{|l|}{ Mood and anxiety symptoms questionnaire II } \\
\hline General distress & 32.03 & 8.11 \\
\hline Anhedonic depression & 43.79 & 5.31 \\
\hline Anxious arousal & 17.53 & 5.71 \\
\hline Mood disorders questionnaire (total score) & 4.22 & 3.18 \\
\hline QIDS SR $_{16}$ (Evaluation) & 18.09 & 2.78 \\
\hline \multicolumn{3}{|l|}{ NEO-five factor inventory } \\
\hline Agreeableness & 32.10 & 6.86 \\
\hline Neuroticism & 34.74 & 6.62 \\
\hline Extraversion & 19.69 & 7.62 \\
\hline Openness & 31.74 & 7.42 \\
\hline Conscientiousness & 24.08 & 8.16 \\
\hline Standard assessment of personality abbreviated & 3.91 & 1.38 \\
\hline Self-administered comorbidity questionnaire & 1.87 & 2.58 \\
\hline \multicolumn{3}{|l|}{ Wechsler abbreviated scale of intelligence } \\
\hline Vocabulary - T-score & 57.62 & 10.29 \\
\hline Matrix reasoning $-\mathrm{T}$-score & 58.13 & 7.19 \\
\hline
\end{tabular}

studies like EMBARC, may generate multiple important hypotheses
Table 5

Number of participants completing biosignature assessments at baseline and week 1 .

\begin{tabular}{|c|c|c|c|c|}
\hline & \multicolumn{2}{|c|}{$\begin{array}{l}\text { Depressed } \\
\text { participants } N=309\end{array}$} & \multicolumn{2}{|c|}{$\begin{array}{l}\text { Healthy controls } \\
\mathrm{N}=40\end{array}$} \\
\hline & $\begin{array}{l}\text { Baseline } \\
\mathrm{N}\end{array}$ & $\begin{array}{l}\text { Week } 1 \\
\mathrm{~N}\end{array}$ & $\begin{array}{l}\text { Baseline } \\
\mathrm{N}\end{array}$ & $\begin{array}{l}\text { Week } 1 \\
\mathrm{~N}\end{array}$ \\
\hline fMRI & 300 & 309 & 40 & 40 \\
\hline Anatomical MRI & 305 & 272 & 40 & 40 \\
\hline DTI & 230 & 19 & 40 & 0 \\
\hline EEG & 300 & 267 & 40 & 39 \\
\hline Behavioral Phenotyping & 300 & 267 & 40 & 39 \\
\hline
\end{tabular}

related to treatment of the indication in their target populations.

The selection of markers, whether biological, clinical, or sociodemographic, should, as in EMBARC, be based on previous studies that showed that those factors were predictors of outcome across groups. Generally, there are an infinite number of possible factors that might be considered, but it would be pointless to include those irrelevant to treatment outcome (not predictors). Most of the remaining are likely to be non-specific predictors, but not moderators, and very likely to be more closely related to the various artifactual influences on treatment response than to specific treatment effects. However, true moderators can only be distinguished by exploration, as is done in EMBARC. Of the actual moderators, some will be quantitative, i.e., they identify subgroups with smaller or larger treatment effects, all with the same preferred treatment. Finally, a small number will be qualitative moderators, i.e., they will identify for which patients one treatment is preferred. These are what are most important to personalized medicine. Then subsequently, mediators can be sought within each of these subgroups defined by the moderators to try to improve response to whichever is the preferred treatment.

There has been limited effort so far in detecting and documenting moderators and mediators (Agras et al., 2000; Arnold et al., 2009; Dusseldorp \& Mechelen, 2014; Frank et al., 2011; Garcia et al., 2010; Owens et al., 2003; Walkup et al., 2003; The MTA Cooperative Group, 1999; Wallace et al., 2012), and even less on developing and comparing different methods for doing so. For this reasons, EMBARC has a dual purpose, first, seeking specific moderators in the context MDD, but also developing insights and methods as to how best such studies in general can and should be done.

\section{Future plans}

There are other large studies underway or recently completed which provide opportunities for collaborative analysis. For example, the International Study to Predict Optimized Treatment in Depression (iSPOT-D) includes 2016 depressed, non-psychotic outpatients recruited in 2 waves, aims to identify treatmentpredictive biomarkers in the first wave and test for replication with the second wave (Williams et al., 2011). Potential areas of overlap between iSPOT-D and EMBARC include clinical assessments, some of the behavioral tests, resting EEG, genetics, and certain structural and functional MRI measures. In addition, EMBARC and iSPOT-D share sertraline as a study medication. The Predictors of Remission in Depression and Individual and Combined Treatment (PReDICT) study randomizes about 400 treatment naïve depressed patients for 12 weeks of either cognitive behavior therapy (CBT), duloxetine, or escitalopram, and including fMRI, immune markers, DNA, and gene expression analysis, and dexamethasone-corticotrophin-releasing hormone (Dex/CHR) testing (Dunlop et al., 2012). However, only EMBARC includes a 
placebo arm for comparison.

Together with other studies currently in process (Tansey et al., 2012; Uher et al., 2010), we may improve the chances of selecting the most efficacious treatment for an individual patient early in treatment.

\section{Conflicts of interest}

Dr. Madhukar H. Trivedi, is or has been an advisor/consultant and received fee from (lifetime disclosure): Abbott Laboratories, Inc., Abdi Ibrahim, Akzo (Organon Pharmaceuticals Inc.), Alkermes, AstraZeneca, Axon Advisors, Bristol-Myers Squibb Company, Cephalon, Inc., Cerecor, CME Institute of Physicians, Concert Pharmaceuticals, Inc., Eli Lilly \& Company, Evotec, Fabre Kramer Pharmaceuticals, Inc., Forest Pharmaceuticals, GlaxoSmithKline, Janssen Global Services, LLC, Janssen Pharmaceutica Products, LP, Johnson \& Johnson PRD, Libby, Lundbeck, Meade Johnson, MedAvante, Medtronic, Merck, Mitsubishi Tanabe Pharma Development America, Inc., Naurex, Neuronetics, Otsuka Pharmaceuticals, Pamlab, ParkeDavis Pharmaceuticals, Inc., Pfizer Inc., PgxHealth, Phoenix Marketing Solutions, Rexahn Pharmaceuticals, Ridge Diagnostics, Roche Products Ltd., Sepracor, SHIRE Development, Sierra, SK Life and Science, Sunovion, Takeda, Tal Medical/Puretech Venture, Targacept, Transcept, VantagePoint, Vivus, and Wyeth-Ayerst Laboratories. In addition, he has received grants/research support from: Agency for Healthcare Research and Quality (AHRQ), Cyberonics, Inc., National Alliance for Research in Schizophrenia and Depression, National Institute of Mental Health and National Institute on Drug Abuse. Dr. Thilo Deckersbach's research has been funded by NIH, NIMH, NARSAD, TSA, IOCDF, Tufts University, DBDAT and Otsuka Pharmaceuticals, he has received honoraria, consultation fees and/or royalties from the MGH Psychiatry Academy, BrainCells Inc., Clintara, LLC, Inc., Systems Research and Applications Corporation, Boston University, the Catalan Agency for Health Technology Assessment and Research, the National Association of Social Workers Massachusetts, the Massachusetts Medical Society, Tufts University, NIDA, NIMH, Oxford University Press, Guilford Press, and Rutledge. He has also participated in research funded by DARPA, NIH, NIA, AHRQ PCORI, Janssen Pharmaceuticals, The Forest Research Institute, Shire Development Inc., Medtronic, Cyberonics, Northstar, and Takeda. Dr. Pat McGrath has received funding from the National Institute of Mental Health, New York State Department of Mental Hygiene, Research Foundation for Mental Hygiene (New York State), Forest Research Laboratories, Sunovion Pharmaceuticals, and Naurex Pharmaceuticals (now Allergan). Dr. Fava has received research support from Abbot Laboratories; Alkermes, Inc.; American Cyanamid; Aspect Medical Systems; AstraZeneca; Avanir Pharmaceuticals; BioResearch; BrainCells Inc.; Bristol-Myers Squibb; CeNeRx BioPharma; Cephalon; Clintara, LLC; Cerecor; Covance; Covidien; Eli Lilly and Company; EnVivo Pharmaceuticals, Inc.; Euthymics Bioscience, Inc.; Forest Pharmaceuticals, Inc.; Ganeden Biotech, Inc.; GlaxoSmithKline; Harvard Clinical Research Institute; Hoffman-LaRoche; Icon Clinical Research; i3 Innovus/Ingenix; Janssen R\&D, LLC; Jed Foundation; Johnson \& Johnson Pharmaceutical Research \& Development; Lichtwer Pharma GmbH; Lorex Pharmaceuticals; Lundbeck Inc.; MedAvante; Methylation Sciences Inc.; National Alliance for Research on Schizophrenia \& Depression (NARSAD); National Center for Complementary and Alternative Medicine (NCCAM); National Institute of Drug Abuse (NIDA); National Institute of Mental Health (NIMH); Neuralstem, Inc.; Novartis AG; Organon Pharmaceuticals; PamLab, LLC.; Pfizer Inc.; Pharmacia-Upjohn; Pharmaceutical Research Associates., Inc.; Pharmavite ${ }^{\circledR}$ LLC; PharmoRx Therapeutics; Photothera; Reckitt Benckiser; Roche Pharmaceuticals; RCT Logic, LLC (formerly Clinical Trials Solutions, LLC); Sanofi-Aventis US LLC;
Shire; Solvay Pharmaceuticals, Inc.; Stanley Medical Research Institute (SMRI); Synthelabo; Tal Medical; Wyeth-Ayerst Laboratories; he has served as advisor or consultant to Abbott Laboratories; Acadia; Affectis Pharmaceuticals AG; Alkermes, Inc.; Amarin Pharma Inc.; Aspect Medical Systems; AstraZeneca; Auspex Pharmaceuticals; Avanir Pharmaceuticals; AXSOME Therapeutics; Bayer AG; Best Practice Project Management, Inc.; Biogen; BioMarin Pharmaceuticals, Inc.; Biovail Corporation; BrainCells Inc; BristolMyers Squibb; CeNeRx BioPharma; Cephalon, Inc.; Cerecor; CNS Response, Inc.; Compellis Pharmaceuticals; Cypress Pharmaceutical, Inc.; DiagnoSearch Life Sciences (P) Ltd.; Dinippon Sumitomo Pharma Co. Inc.; Dov Pharmaceuticals, Inc.; Edgemont Pharmaceuticals, Inc.; Eisai Inc.; Eli Lilly and Company; EnVivo Pharmaceuticals, Inc.; ePharmaSolutions; EPIX Pharmaceuticals, Inc.; Euthymics Bioscience, Inc.; Fabre-Kramer Pharmaceuticals, Inc.; Forest Pharmaceuticals, Inc.; Forum Pharmaceuticals; GenOmind, LLC; GlaxoSmithKline; Grunenthal GmbH; i3 Innovus/Ingenis; Intracellular; Janssen Pharmaceutica; Jazz Pharmaceuticals, Inc.; Johnson \& Johnson Pharmaceutical Research \& Development, LLC; Knoll Pharmaceuticals Corp.; Labopharm Inc.; Lorex Pharmaceuticals; Lundbeck Inc.; MedAvante, Inc.; Merck \& Co., Inc.; MSI Methylation Sciences, Inc.; Naurex, Inc.; Nestle Health Sciences; Neuralstem, Inc.; Neuronetics, Inc.; NextWave Pharmaceuticals; Novartis AG; Nutrition 21; Orexigen Therapeutics, Inc.; Organon Pharmaceuticals; Osmotica; Otsuka Pharmaceuticals; Pamlab, LLC.; Pfizer Inc.; PharmaStar; Pharmavite ${ }^{\circledR}$ LLC.; PharmoRx Therapeutics; Precision Human Biolaboratory; Prexa Pharmaceuticals, Inc.; Puretech Ventures; PsychoGenics; Psylin Neurosciences, Inc.; RCT Logic, LLC Formerly Clinical Trials Solutions, LLC; Rexahn Pharmaceuticals, Inc.; Ridge Diagnostics, Inc.; Roche; Sanofi-Aventis US LLC.; Sepracor Inc.; Servier Laboratories; Schering-Plough Corporation; Solvay Pharmaceuticals, Inc.; Somaxon Pharmaceuticals, Inc.; Somerset Pharmaceuticals, Inc.; Sunovion Pharmaceuticals; Supernus Pharmaceuticals, Inc.; Synthelabo; Taisho Pharmaceutical; Takeda Pharmaceutical Company Limited; Tal Medical, Inc.; Tetragenex Pharmaceuticals, Inc.; TransForm Pharmaceuticals, Inc.; Transcept Pharmaceuticals, Inc.; Vanda Pharmaceuticals, Inc.; VistaGen; he has received speaking or publishing fees from Adamed, Co; Advanced Meeting Partners; American Psychiatric Association; American Society of Clinical Psychopharmacology; AstraZeneca; Belvoir Media Group; Boehringer Ingelheim GmbH; Bristol-Myers Squibb; Cephalon, Inc.; CME Institute/Physicians Postgraduate Press, Inc.; Eli Lilly and Company; Forest Pharmaceuticals, Inc.; GlaxoSmithKline; Imedex, LLC; MGH Psychiatry Academy/Primedia; MGH Psychiatry Academy/Reed Elsevier; Novartis AG; Organon Pharmaceuticals; Pfizer Inc.; PharmaStar; United BioSource, Corp.; Wyeth-Ayerst Laboratories; he has equity holdings in Compellis and PsyBrain, Inc.; he has a patent for Sequential Parallel Comparison Design (SPCD), which are licensed by MGH to Pharmaceutical Product Development, LLC (PPD); and patent application for a combination of Ketamine plus Scopolamine in Major Depressive Disorder (MDD), licensed by MGH to Biohaven; and he receives copyright royalties for the MGH Cognitive \& Physical Functioning Questionnaire (CPFQ), Sexual Functioning Inventory (SFI), Antidepressant Treatment Response Questionnaire (ATRQ), Discontinuation-Emergent Signs \& Symptoms (DESS), Symptoms of Depression Questionnaire (SDQ), and SAFER; Lippincott, Williams \& Wilkins; Wolkers Kluwer; World Scientific Publishing Co. Pte.Ltd.

Dr. Ramin Parsey reports no relevant or material financial interests that relate to the research described in this paper. Dr. Benji Kurian has received research grant support from the following organizations: Targacept, Inc., Pfizer, Inc., Johnson \& Johnson, Evotec, Rexahn, Naurex, Forest Pharmaceuticals and the National Institute of Mental Health (NIMH). Mary L. Phillips has received funding from NIMH and the Emmerling-Pittsburgh Foundation. Dr. 
Oquendo receives royalties for use of the Columbia Suicide Severity Rating Scale and received financial compensation from Pfizer for the safety evaluation of a clinical facility, unrelated to this study. She is the recipient of a grant from Eli Lilly to support a year's salary for the Lilly Suicide Scholar, Enrique Baca-Garcia, M.D., Ph.D.; she has received unrestricted educational grants and/or lecture fees from Astra-Zeneca, Bristol Myers Squibb, Eli Lilly, Janssen, Otsuko, Pfizer, Sanofi-Aventis, and Shire. Her family owns stock in Bristol Myers Squibb. Gerard Bruder have no conflicts of interest with respect to this paper. Over the past three years, Dr. Pizzagalli has received honoraria/consulting fees from Advanced Neurotechnology North America, AstraZeneca, Otsuka America Pharmaceutical, Pfizer, and Servier for activities unrelated to this project. Dr. Marisa Toups has received travel funds from Janssen Research and Development and currently receives compensation for serving on a data safety and monitoring board for Otsuka Pharmaceuticals. Dr. Crystal Cooper, Dr. Phil Adams, and Dr. Sarah Weyandt report no competing interests. Drs. Morris and Grannemann do have any conflicting interests to report. Dr. Todd Ogden reports no conflicting interests. Dr. Randy Buckner is a paid consultant for Pfizer, Inc. Dr. Melvin McInnis has no conflicts of interest with respect to this paper. Dr. Helena C. Kraemer does not have any conflicts. Dr. Eva Petkova reports no conflicting interests. Dr. Thomas Carmody does not report any conflicting interests. In the past two years, Dr. Myrna Weissman received funding from the National Institute of Mental Health (NIMH), the National Institute on Drug Abuse (NIDA), the National Alliance for Research on Schizophrenia and Depression (NARSAD), the Sackler Foundation, the Templeton Foundation; and receives royalties from the Oxford University Press, Perseus Press, the American Psychiatric Association Press, and MultiHealth Systems.

\section{Contributors}

All authors contributed to the original content and design for this paper. Drs. Eva Petkova (New York University), Thomas Carmody (UT Southwestern Medical Center) and Helena Kramer (Stanford University) developed the statistical analysis sections and Dr. Madhukar Trivedi wrote the first draft of the manuscript. All authors contributed to and approved the final manuscript for publication in the Journal of Psychiatric Research.

\section{Role of funding source}

The EMBARC study was supported by the National Institute of Mental Health of the National Institutes of Health under award numbers U01MH092221 (Trivedi, M.H.) and U01MH092250 (McGrath, P.J., Parsey, R.V., Weissman, M.M.). The content is solely the responsibility of the authors and does not necessarily represent the official views of the National Institutes of Health. Valeant Pharmaceuticals donated the Wellbutrin XL used in the study. This work was supported by the EMBARC National Coordinating Center at UT Southwestern Medical Center, Madhukar H. Trivedi, M.D., Coordinating PI, and the Data Center at Columbia and Stony Brook Universities.

\section{Acknowledgments}

This study was supported in part by Valeant Pharmaceuticals who donated the Wellbutrin XL used in this study. We would also like to thank the EMBARC National Coordinating Center at UT Southwestern Medical Center, Madhukar H. Trivedi, M.D., Coordinating PI, and the Data Center at Columbia University. We also thank Carol A. Tamminga, M.D., Communities Foundation of Texas, Inc. Chair in Brain Science, and Chair, Department of Psychiatry,
University of Texas Southwestern Medical Center for administrative support and Cassandra Hatt for assistance with manuscript preparation and submission.

\section{References}

Agras, W.S., Walsh, B.T., Fairburn, C.G., Wilson, G.T., Kraemer, H.C., 2000 A multicenter comparison of cognitive-behavioral therapy and interpersonal psychotherapy for bulimia nervosa. Archives General Psychiatry 57, 4599-4466.

Almeida, J.R., Versace, A., Mechelli, A., Hassel, S., Quevedo, K., Kupfer, D.J., Phillips, M.L., 2009. Abnormal amygdala-prefrontal effective connectivity to happy faces differentiates bipolar from major depression. Biol. Psychiatry 66, 451-459.

American Psychiatric Association, 2000. Diagnostic and Statistical Manual of Mental Disorders - Text Revision, fourth ed. American Psychiatric Press, Washington DC.

Anand, A., Li, Y., Wang, Y., Wu, J., Gao, S., Bukhari, L., Mathews, V.P., Kalnin, A., Lowe, M.J., 2005. Activity and connectivity of brain mood regulating circuit in depression: a functional magnetic resonance study. Biol. Psychiatry 57, 1079-1088.

Arnold, L.E., Farmer, C., Kraemer, H.C., Davies, M., Witwer, A., Chuang, S., DiSilvestro, R., McDougle, C., McCracken, J., Bitiello, B., Aman, M., Scahill, L., Posey, D., Moderators, Swiezy N., 2009. Mediators, and other predictors of risperidone response in children with autistic disorder and irritability. J. Child Adolesc. Psychopharmacol. 20, 83-93.

Bruder, G.E., Sedoruk, J.P., Stewart, J.W., McGrath, P.J., Quitkin, F.M., Tenke, C.E., 2008. Electroencephalographic alpha measures predict therapeutic response to a selective serotonin reuptake inhibitor antidepressant: pre- and post-treatment findings. Biol. Psychiatry 63, 1171-1177.

Bruder, G.T., Kayser, C.E. 2013. J. electrophysiological predictors of clinical response to antidepressants. In: JJ Mann, P.M. (Ed.), The Clinical Handbook for the Management of Mood Disorders. Cambridge, UK. Cambridge University Press, pp. $380-393$.

Caligiuri, M.P., Gentili, V., Eberson, S., Kelsoe, J., Rapaport, M., Gillin, J.C., 2003. A quantitative neuromotor predictor of antidepressant non-response in patients with major depression. J. Affect Disord. 77, 135-141.

Campbell, S., Marriott, M., Nahmias, C., MacQueen, G.M., 2004. Lower hippocampal volume in patients suffering from depression: a meta-analysis. Am. J. Psychiatry 161, 598-607.

Chandler, G.M., Iosifescu, D.V., Pollack, M.H., Targum, S.D., Fava, M., 2010. Research: validation of the Massachusetts general hospital antidepressant treatment history questionnaire (ATRQ). CNS Neurosci. Ther. 16, 322-325.

Dalby, R.B., Frandsen, J., Chakravarty, M.M., Ahdidan, J., Sorensen, L., Rosenberg, R., Videbech, P., Ostergaard, L., 2010. Depression severity is correlated to the integrity of white matter fiber tracts in late-onset major depression. Psychiatry Res. 184, 38-48.

Dunlop, B.W., Binder, E.B., Cubells, J.F., Goodman, M.M., Kelley, M.E., Kinkead, B., Kutner, M., Nemeroff, C.B., Newport, D.J., Owens, M.J., Pace, T.W., Ritchie, J.C., Rivera, V.A., Westen, D., Craighead, W.E., Mayberg, H.S., 2012. Predictors of remission in depression to individual and combined treatments (PReDICT): study protocol for a randomized controlled trial. Trials 13, 106.

Dusseldorp, E., Mechelen, I., 2014. Dusseldorp E. and Mechelen I., Qualitative interaction trees: a tool to identify qualitative treatment-subgroup interactions statistics in medicine. Stat. Med. 33, 219-237.

Emmett, M.R., Kroes, R.A., Moskal, J.R., Conrad, C.A., Priebe, W., Laezza, F., MeyerBaese, A., Nilsson, C.L., 2014. Integrative biological analysis for neuropsychopharmacology. Neuropsychopharmacology 39, 5-23.

Etkin, A., Egner, T., Kalisch, R., 2011. Emotional processing in anterior cingulate and medial prefrontal cortex. Trends Cogn. Sci. 15, 85-93.

Etkin, A., Egner, T., Peraza, D.M., Kandel, E.R., Hirsch, J., 2006. Resolving emotional conflict: a role for the rostral anterior cingulate cortex in modulating activity in the amygdala. Neuron $51,871-882$.

Fava, M., Alpert, J.E., Carmin, C.N., Wisniewski, S.R., Trivedi, M.H., Biggs, M.M., Shores-Wilson, K., Morgan, D., Schwartz, T., Balasubramani, G.K., Rush, A.J., 2004. Clinical correlates and symptom patterns of anxious depression among patients with major depressive disorder in STAR*D. Psychol. Med. 34, 1299-1308.

Fava, M., Rankin, M.A., Wright, E.C., Alpert, J.E., Nierenberg, A.A., Pava, J., Rosenbaum, J.F., 2000. Anxiety disorders in major depression. Compr. Psychiatry $41,97-102$

Fava, M., Rush, A.J., Trivedi, M.H., Nierenberg, A.A., Thase, M.E., Sackeim, H.A., Quitkin, F.M., Wisniewski, S., Lavori, P.W., Rosenbaum, J.F., Kupfer, D.J., 2003. Background and rationale for the sequenced treatment alternatives to relieve depression (STAR*D) study. Psychiatr. Clin. North Am. 26, 457-494.

Flament, M.F., Lane, R.M., Zhu, R., Ying, Z., 1999. Predictors of an acute antidepressant response to fluoxetine and sertraline. Int. Clin. Psychopharmacol. 14, 259-275.

Forbes, E.E., Olino, T.M., Ryan, N.D., Birmaher, B., Axelson, D., Moyles, D.L., Dahl, R.E., 2010a. Reward-related brain function as a predictor of treatment response in adolescents with major depressive disorder. Cogn. Affect Behav. Neurosci. 10, $107-118$.

Forbes, E.E., Ryan, N.D., Phillips, M.L., Manuck, S.B., Worthman, C.M., Moyles, D.L. 
Tarr, J.A., Sciarrillo, S.R., Dahl, R.E., 2010b. Healthy adolescents' neural response to reward: associations with puberty, positive affect, and depressive symptoms. J. Am. Acad. Child Adolesc. Psychiatry 49, 162-172 e161-165.

Frank, E., Cassano, G.B., Rucci, P., Thompson, W.K., Kraemer, H.C., Fagiolini, A., Maggi, L., Kupfer, D.J., Shear, M.K., Houck, P.R., Calugi, S., Grochocinski, V.J., Scocco, P., Buttenfield, J., Forgione, R.N., 2011. Predictors and moderators of time to remission of major depression with interpersonal psychotherapy and SSRI pharmacotherapy. Psychol. Med. 41, 151-162.

Fu, C.H., Williams, S.C., Cleare, A.J., Brammer, M.J., Walsh, N.D., Kim, J., Andrew, C.M., Pich, E.M., Williams, P.M., Reed, L.J., Mitterschiffthaler, M.T., Suckling, J., Bullmore, E.T., 2004. Attenuation of the neural response to sad faces in major depression by antidepressant treatment: a prospective, event-related functional magnetic resonance imaging study. Arch. Gen. Psychiatry 61, 877-889.

Garcia, A.M., Sapyta, J.J., Moore, P.S., Freeman, J.B., Franklin, M.E., March, J.S., Foa, E.B., 2010. Predictors and moderators of treatment outcome in the pediatric obsessive compulsive treatment study (POTS I). J. Am. Acad. Child Adolesc, Psychiatry 49, 1024-1033.

Gorlyn, M., Keilp, J.G., Grunebaum, M.F., Taylor, B.P., Oquendo, M.A., Bruder, G.E., Stewart, J.W., Zalsman, G., Mann, J.J., 2008. Neuropsychological characteristics as predictors of SSRI treatment response in depressed subjects. J. Neural Transm. 115, 1213-1219.

Gunter, L., Zhu, J., Murphy, S.A., 2011. Variable selection for qualitative interactions. Stat. Methodol. 1, 42-55.

Haber, S.N., Knutson, B., 2010. The reward circuit: linking primate anatomy and human imaging. Neuropsychopharmacology 35, 4-26.

Hariri, A.R., Mattay, V.S., Tessitore, A., Kolachana, B., Fera, F., Goldman, D., Egan, M.F., Weinberger, D.R., 2002. Serotonin transporter genetic variation and the response of the human amygdala. Science 297, 400-403.

Harvey, P.O., Pruessner, J., Czechowska, Y., Lepage, M., 2007. Individual differences in trait anhedonia: a structural and functional magnetic resonance imaging study in non-clinical subjects. Mol. Psychiatry 12 (703), 767-775.

Heller, A.S., Johnstone, T., Shackman, A.J., Light, S.N., Peterson, M.J., Kolden, G.G., Kalin, N.H., Davidson, R.J., 2009. Reduced capacity to sustain positive emotion in major depression reflects diminished maintenance of fronto-striatal brain activation. Proc. Natl. Acad. Sci. U. S. A. 106, 22445-22450.

Henderson, R., Ansell, P., Alshibani, D., 2010. Regret-regression for optimal dynamic treatment regimes. Biometrics 66, 1192-1201.

Herrera-Guzman, I., Gudayol-Ferre, E., Herrera-Guzman, D., Guardia-Olmos, J., Hinojosa-Calvo, E., Herrera-Abarca, J.E., 2009. Effects of selective serotonin reuptake and dual serotonergic-noradrenergic reuptake treatments on memory and mental processing speed in patients with major depressive disorder. J. Psychiatr. Res. 43, 855-863.

Herrera-Guzman, I., Gudayol-Ferre, E., Lira-Mandujano, J., Herrera-Abarca, J., Herrera-Guzman, D., Montoya-Perez, K., Guardia-Olmos, J., 2008. Cognitive predictors of treatment response to bupropion and cognitive effects of bupropion in patients with major depressive disorder. Psychiatry Res. 160, 72-82.

Holmes, A.J., Bogdan, R., Pizzagalli, D.A., 2010. Serotonin transporter genotype and action monitoring dysfunction: a possible substrate underlying increased vulnerability to depression. Neuropsychopharmacology 35, 1186-1197.

Holmes, A.J., Pizzagalli, D.A., 2008. Spatiotemporal dynamics of error processing dysfunctions in major depressive disorder. Arch. Gen. Psychiatry 65, 179-188.

James, G.M., J.W, Zhu, J., 2009. Functional linear regression that interpretable. Ann. Statistics 37, 2083-2108.

Jarnum, H., Eskildsen, S.F., Steffensen, E.G., Lundbye-Christensen, S., Simonsen, C.W., Thomsen, I.S., Frund, E.T., Theberge, J., Larsson, E.M., 2011. Longitudinal MRI study of cortical thickness, perfusion, and metabolite levels in major depressive disorder. Acta Psychiatr. Scand. 124, 435-446.

Julian, L.J., Mohr, D.C., 2006. Cognitive predictors of response to treatment for depression in multiple sclerosis. J. Neuropsychiatry Clin. Neurosci. 18, 356-363.

Kalayam, B., Alexopoulos, G.S., 1999. Prefrontal dysfunction and treatment response in geriatric depression. Arch. Gen. Psychiatry 56, 713-718.

Knutson, B., Bhanji, J.P., Cooney, R.E., Atlas, L.Y., Gotlib, I.H., 2008. Neural responses to monetary incentives in major depression. Biol. Psychiatry 63, 686-692.

Koolschijn, P.C., van Haren, N.E., Lensvelt-Mulders, G.J., Hulshoff Pol, H.E., Kahn, R.S., 2009. Brain volume abnormalities in major depressive disorder: a metaanalysis of magnetic resonance imaging studies. Hum. Brain Mapp. 30, 3719-3735.

Korb, A.S., Hunter, A.M., Cook, I.A., Leuchter, A.F., 2009. Rostral anterior cingulate cortex theta current density and response to antidepressants and placebo in major depression. Clin. Neurophysiol. 120, 1313-1319.

Kraemer, H.C., 2013. Discovering, comparing, and combining moderators of treatment on outcome after randomized clinical trials: a parametric approach. Stat. Med. 32, 1964-1973.

Kraemer, H.C., Stice, E., Kazdin, A., Offord, D., Kupfer, D., 2001. How do risk factors work together? Mediators, moderators, and independent, overlapping, and proxy risk factors. Am. J. Psychiatry 158, 848-856.

Krishnan, V., Nestler, E.J., 2008. The molecular neurobiology of depression. Nature 455, 894-902.

Kumar, P., Waiter, G., Ahearn, T., Milders, M., Reid, I., Steele, J.D., 2008. Abnormal temporal difference reward-learning signals in major depression. Brain 131, 2084-2093.

Levinson, D.F., Evgrafov, O.V., Knowles, J.A., Potash, J.B., Weissman, M.M., Scheftner, W.A., Depaulo Jr., J.R., Crowe, R.R., Murphy-Eberenz, K., Marta, D.H., McInnis, M.G., Adams, P., Gladis, M., Miller, E.B., Thomas, J., Holmans, P., 2007. Genetics of recurrent early-onset major depression (GenRED): significant linkage on chromosome 15q25-q26 after fine mapping with single nucleotide polymorphism markers. Am. J. Psychiatry 164, 259-264.

Linka, T., Muller, B.W., Bender, S., Sartory, G., 2004. The intensity dependence of the auditory evoked N1 component as a predictor of response to Citalopram treatment in patients with major depression. Neurosci. Lett. 367, 375-378.

Linka, T., Muller, B.W., Bender, S., Sartory, G., Gastpar, M., 2005. The intensity dependence of auditory evoked ERP components predicts responsiveness to reboxetine treatment in major depression. Pharmacopsychiatry 38, 139-143.

Lui, S., Parkes, L.M., Huang, X., Zou, K., Chan, R.C., Yang, H., Zou, L., Li, D., Tang, H. Zhang, T., Li, X., Wei, Y., Chen, L., Sun, X., Kemp, G.J., Gong, Q.Y., 2009. Depressive disorders: focally altered cerebral perfusion measured with arterial spinlabeling MR imaging. Radiology 251, 476-484.

Marquand, A.F., Mourao-Miranda, J., Brammer, M.J., Cleare, A.J., Fu, C.H., 2008 Neuroanatomy of verbal working memory as a diagnostic biomarker for depression. Neuroreport 19, 1507-1511.

McGrath, C.L., Kelley, M.E., Holtzheimer, P.E., Dunlop, B.W., Craighead, W.E. Franco, A.R., Craddock, R.C., Mayberg, H.S., 2013. Toward a neuroimaging treatment selection biomarker for major depressive disorder. JAMA Psychiatry 70, $821-829$.

Mitchell, T.M., Hutchinson, R., Niculescu, R.S., Pereira, F., Wang, X.R., Just, M., Newman, S., 2004. Learning to decode cognitive states from from brain images. Mach. Learn. 57, 145-175.

Mourao-Miranda, J., Bokde, A.L., Born, C., Hampel, H., Stetter, M., 2005. Classifying brain states and determining the discriminating activation patterns: support vector machine on functional MRI data. Neuroimage 28, 980-995.

Mulert, C., Juckel, G., Brunnmeier, M., Karch, S., Leicht, G., Mergl, R., Moller, H.J., Hegerl, U., Pogarell, O., 2007. Prediction of treatment response in major depression: integration of concepts. J. Affect Disord. 98, 215-225.

Murphy, S.A., 2003. Optimal dynamic treatment regimes. J. Royal Stat. Soc. Ser. B 65, $331-355$.

Nemeroff, C.B., Heim, C.M., Thase, M.E., Klein, D.N., Rush, A.J., Schatzberg, A.F., Ninan, P.T., McCullough Jr., J.P., Weiss, P.M., Dunner, D.L., Rothbaum, B.O., Kornstein, S., Keitner, G., Keller, M.B., 2003. Differential responses to psychotherapy versus pharmacotherapy in patients with chronic forms of major depression and childhood trauma. Proc. Natl. Acad. Sci. U. S. A. 100, 14293-14296.

Nierenberg, A.A., 2003. Predictors of response to antidepressants general principles and clinical implications. Psychiatr. Clin. North Am. 26, 345-352.

Owens, E.B., Hinshaw, S.P., Kraemer, H.C., Arnold, L.E., Abikoff, H.B., Cantwell, D.P. Conners, C.K., Elliot, G., Greenhill, L.L., Hechtman, L., Hoza, B., Jensen, P.S., March, J.S., Newcorn, J.H., Pelham, W.E., Richters, J.E., Schiller, E.P., Severe, J.B. Swanson, J.M., Vereen, D., Vitiello, B., Wells, K.C., Wigal, T., 2003. What treatment for whom for ADHD: moderators of treatment response in the MTA J. Consult. Clin. Psychol. 71, 540-552.

Peterson, B.S., Warner, V., Bansal, R., Zhu, H., Hao, X., Liu, J., Durkin, K., Adams, P.B., Wickramaratne, P., Weissman, M.M., 2009. Cortical thinning in persons at increased familial risk for major depression. Proc. Natl. Acad. Sci. U. S. A. 106, 6273-6278.

Pezawas, L., Meyer-Lindenberg, A., Drabant, E.M., Verchinski, B.A., Munoz, K.E., Kolachana, B.S., Egan, M.F., Mattay, V.S., Hariri, A.R., Weinberger, D.R., 2005. 5HTTLPR polymorphism impacts human cingulate-amygdala interactions: a genetic susceptibility mechanism for depression. Nat. Neurosci. 8, 828-834.

Phillips, M.L., Ladouceur, C.D., Drevets, W.C., 2008. A neural model of voluntary and automatic emotion regulation: implications for understanding the pathophysiology and neurodevelopment of bipolar disorder. Mol. Psychiatry 13 (829), $833-857$.

Pizzagalli, D., Pascual-Marqui, R.D., Nitschke, J.B., Oakes, T.R., Larson, C.L. Abercrombie, H.C., Schaefer, S.M., Koger, J.V., Benca, R.M., Davidson, R.J., 2001 Anterior cingulate activity as a predictor of degree of treatment response in major depression: evidence from brain electrical tomography analysis. Am. J. Psychiatry 158, 405-415.

Pizzagalli, D.A., 2011. Frontocingulate dysfunction in depression: toward biomarkers of treatment response. Neuropsychopharmacology 36, 183-206.

Pizzagalli, D.A., Evins, A.E., Schetter, E.C., Frank, M.J., Pajtas, P.E., Santesso, D.L. Culhane, M., 2008. Single dose of a dopamine agonist impairs reinforcement learning in humans: behavioral evidence from a laboratory-based measure of reward responsiveness. Psychopharmacol. Berl. 196, 221-232.

Pizzagalli, D.A., Peccoralo, L.A., Davidson, R.J., Cohen, J.D., 2006. Resting anterior cingulate activity and abnormal responses to errors in subjects with elevated depressive symptoms: a 128-channel EEG study. Hum. Brain Mapp. 27, 185-201.

Reiss, P.T., Ogden, R.T., 2010. Functional generalized linear models with images as predictors. Biometrics 66, 61-69.

Rentzsch, J., Adli, M., Wiethoff, K., Gomez-Carrillo de Castro, A., Gallinat, J., 2014. Pretreatment anterior cingulate activity predicts antidepressant treatment response in major depressive episodes. Eur. Arch. Psychiatry Clin. Neurosci 264 $213-223$.

Robertson, B., Wang, L., Diaz, M.T., Aiello, M., Gersing, K., Beyer, J., Mukundan Jr., S., McCarthy, G., Doraiswamy, P.M., 2007. Effect of bupropion extended release on negative emotion processing in major depressive disorder: a pilot functional magnetic resonance imaging study. J. Clin. Psychiatry 68, 261-267.

Robins, J., Orellana, L., Rotnitzky, A., 2008. Estimation and extrapolation of optimal treatment and testing strategies. Stat. Med. 27, 4678-4721.

Ruhe, H.G., Booij, J., Veltman, D.J., Michel, M.C., Schene, A.H., 2012. Successful pharmacologic treatment of major depressive disorder attenuates amygdala 
activation to negative facial expressions: a functional magnetic resonance imaging study. J. Clin. Psychiatry 73, 451-459.

Rush, A.J., Trivedi, M.H., Wisniewski, S.R., Nierenberg, A.A., Stewart, J.W., Warden, D., Niederehe, G., Thase, M.E., Lavori, P.W., Lebowitz, B.D., McGrath, P.J. Rosenbaum, J.F., Sackeim, H.A., Kupfer, D.J., Luther, J., Fava, M., 2006. Acute and longer-term outcomes in depressed outpatients requiring one or severa treatment steps: a STAR*D report. Am. J. Psychiatry 163, 1905-1917.

Rush, A.J., Wisniewski, S.R., Warden, D., Luther, J.F., Davis, L.L., Fava, M. Nierenberg, A.A., Trivedi, M.H., 2008. Selecting among second-step antidepressant medication monotherapies: predictive value of clinical, demographic, or first-step treatment features. Arch. Gen. Psychiatry 65, 870-880.

Santesso, D.L., Dillon, D.G., Birk, J.L., Holmes, A.J., Goetz, E., Bogdan, R. Pizzagalli, D.A., 2008. Individual differences in reinforcement learning: behavioral, electrophysiological, and neuroimaging correlates. Neuroimage 42 , 807-816.

Sato, J.R., Fujita, A., Thomaz, C.E., Martin Mda, G., Mourao-Miranda, J., Brammer, M.J., Amaro Junior, E., 2009. Evaluating SVM and MLDA in the extraction of discriminant regions for mental state prediction. Neuroimage 46, 105-114.

Schultz, W., 2007. Multiple dopamine functions at different time courses. Annu. Rev. Neurosci. 30, 259-288.

Sheline, Y.I., Barch, D.M., Donnelly, J.M., Ollinger, J.M., Snyder, A.Z., Mintun, M.A 2001. Increased amygdala response to masked emotional faces in depressed subjects resolves with antidepressant treatment: an fMRI study. Biol. Psychiatry 50, 651-658.

Sheline, Y.I., Price, J.L., Yan, Z., Mintun, M.A., 2010. Resting-state functional MRI in depression unmasks increased connectivity between networks via the dorsa nexus. Proc. Natl. Acad. Sci. U. S. A. 107, 11020-11025.

Stewart, J.W., McGrath, P.J., Quitkin, F.M., Harrison, W., Markowitz, J., Wager, S., Leibowitz, M.R., 1989. Relevance of DMS-III depressive subtype and chronicity of antidepressant efficacy in atypical depression. Differential response to phenelzine, imipramine, and placebo. Arch. Gen. Psychiatry 46, 1080-1087.

Surguladze, S.A., Radua, J., El-Hage, W., Gohier, B., Sato, J.R., Kronhaus, D.M. Proitsi, P., Powell, J., Phillips, M.L., 2012. Interaction of catechol O-methyltransferase and serotonin transporter genes modulates effective connectivity in a facial emotion-processing circuitry. Transl. Psychiatry 2, e70.

Suslow, T., Konrad, C., Kugel, H., Rumstadt, D., Zwitserlood, P., Schoning, S. Ohrmann, P., Bauer, J., Pyka, M., Kersting, A., Arolt, V., Heindel, W. Dannlowski, U., 2010. Automatic mood-congruent amygdala responses to masked facial expressions in major depression. Biol. Psychiatry 67, 155-160.

Tansey, K.E., Guipponi, M., Perroud, N., Bondolfi, G., Domenici, E., Evans, D. Hall, S.K., Hauser, J., Henigsberg, N., Hu, X., Jerman, B., Maier, W., Mors, O. O'Donovan, M., Peters, T.J., Placentino, A., Rietschel, M., Souery, D. Aitchison, K.J., Craig, I., Farmer, A., Wendland, J.R., Malafosse, A., Holmans, P., Lewis, G., Lewis, C.M., Stensbol, T.B., Kapur, S., McGuffin, P., Uher, R., 2012. Genetic predictors of response to serotonergic and noradrenergic antidepressants in major depressive disorder: a genome-wide analysis of individual-level data and a meta-analysis. PLoS Med. 9, e1001326.

Taylor, B.P., Bruder, G.E., Stewart, J.W., McGrath, P.J., Halperin, J., Ehrlichman, H., Quitkin, F.M., 2006. Psychomotor slowing as a predictor of fluoxetine nonresponse in depressed outpatients. Am. J. Psychiatry 163, 73-78.

Taylor, W.D., Kuchibhatla, M., Payne, M.E., Macfall, J.R., Sheline, Y.I., Krishnan, K.R Doraiswamy, P.M., 2008. Frontal white matter anisotropy and antidepressant remission in late-life depression. PLoS One 3, e3267.

Tenke, C.E., Kayser, J., Manna, C.G., Fekri, S., Kroppmann, C.J., Schaller, J.D. Alschuler, D.M. Stewart, J.W., McGrath, P.., Bruder, G.E., 2011. Current source density measures of electroencephalographic alpha predict antidepressant treatment response. Biol. Psychiatry 70, 388-394.

The MTA Cooperative Group, 1999. Moderators and Mediators of Treatment Response for Children with Attention-deficit/hyperactivity Disorder, 56, pp. 1088-1096.

Trivedi, M.H., 2013. Modeling predictors, moderators and mediators of treatment outcome and resistance in depression. Biol. Psychiatry 74, 2-4.

Trivedi, M.H., Rush, A.J., Wisniewski, S.R., Nierenberg, A.A., Warden, D., Ritz, L., Norquist, G., Howland, R.H., Lebowitz, B., McGrath, P.J., Shores-Wilson, K., Biggs, M.M., Balasubramani, G.K., Fava, M., Team, S.D.S., 2006. Evaluation of outcomes with citalopram for depression using measurement-based care in STAR*D: implications for clinical practice. Am. J. Psychiatry 163, 28-40.

Uher, R., Huezo-Diaz, P., Perroud, N., Smith, R., Rietschel, M., Mors, O., Hauser, J., Maier, W. Kozel, D., Henigsberg, N., Barreto, M., Placentino, A., Dernovsek, M.Z. Schulze, T.G., Kalember, P., Zobel, A., Czerski, P.M., Larsen, E.R., Souery, D., Giovannini, C., Gray, J.M., Lewis, C.M., Farmer, A., Aitchison, K.J., McGuffin, P., Craig, I., 2009. Genetic predictors of response to antidepressants in the GENDEP project. Pharmacogenomics J. 9, 225-233.

Uher, R., Perroud, N., Ng, M.Y., Hauser, J., Henigsberg, N., Maier, W., Mors, O., Placentino, A., Rietschel, M., Souery, D., Zagar, T., Czerski, P.M., Jerman, B., Larsen, E.R., Schulze, T.G., Zobel, A., Cohen-Woods, S., Pirlo, K., Butler, A.W., Muglia, P., Barnes, M.R., Lathrop, M., Farmer, A., Breen, G., Aitchison, K.J., Craig, I., Lewis, C.M., McGuffin, P., 2010. Genome-wide pharmacogenetics of antidepressant response in the GENDEP project. Am. J. Psychiatry 167, 555-564.

Ulrich, G., Remfordt, E., Frick, K., 1986. The topographical distribution of alphaactivity in the resting eeg of endogenous-depressive inpatients with and without clinical-response to pharmacotherapy. Pharmacopsychiatry 19, $272-273$.

Victor, T.A., Furey, M.L., Fromm, S.J., Ohman, A., Drevets, W.C., 2010. Relationship between amygdala responses to masked faces and mood state and treatment in major depressive disorder. Arch. Gen. Psychiatry 67, 1128-1138.

Walkup, J.T., Labellarte, M.J., Riddle, M.A., Rine, D., Greenhill, L., Klein, R., Davies, M., Sweeney, M., Fu, C., Abikoff, H., Hack, S., Klee, B., McCracken, J., Bergman, L., Piacentini, J., March, J., Compton, S., Robinson, J., O'Hara, T., Baker, S., Vitiello, B., Ritz, L., Roper, M., 2003. Searching for moderators and mediators of pharmacological treatment effects in children and adolexcents with anxiety disorders. J. Am. Acad. Child Adolesc. Psychiatry 42, 13-21.

Wallace, M.L., Frank, E., Kraemer, H.C., 2012. A Novel Approach for Developing and Interpreting Treatment Moderator Profiles in Randomized Clinical Trials. In Submission.

Wallace, M.L., Frank, E., Kraemer, H.C., 2013. A novel approach for developing and interpreting treatment moderator profiles in randomized clinical trials. JAMA Psychiatry 70, 1241-1247.

Weissman, M.M., Wickramaratne, P., Merikangas, K.R., Leckman, J.F., Prusoff, B.A., Caruso, K.A., Kidd, K.K., Gammon, G.D., 1984. Onset of major depression in early adulthood. Increased familial loading and specificity. Arch. Gen. Psychiatry 41, 1136-1143.

Williams, L.M., Rush, A.J., Koslow, S.H., Wisniewski, S.R., Cooper, N.J., Nemeroff, C.B., Schatzberg, A.F., Gordon, E., 2011. International study to predict optimized treatment for depression (iSPOT-D), a randomized clinical trial: rationale and protocol. Trials 12, 4.

Wisniewski, S.R., Rush, A.J., Balasubramani, G.K., Trivedi, M.H., Nierenberg, A.A., Investigators, S., 2006. Self-rated global measure of the frequency, intensity, and burden of side effects. J. Psychiatr. Pract. 12, 71-79.

Zhao, Y., Zeng, D., Rush, A.J., Kosorok, M.R., 2012. Estimating individualized treatment rules using outcome weighted learning. J. Am. Stat. Assoc. 107, 1106-1118. 